\title{
Carbon Nanotubes as Active Components for Gas Sensors
}

\author{
Wei-De Zhang and Wen-Hui Zhang \\ Nano Science Research Center, School of Chemistry and Chemical Engineering, South China University of Technology, \\ 381 Wushan Road, Guangzhou 510640, China \\ Correspondence should be addressed to Wei-De Zhang, zhangwd@scut.edu.cn
}

Received 24 December 2008; Revised 30 March 2009; Accepted 13 April 2009

Recommended by Michele Penza

The unique structure of carbon nanotubes endows them with fantastic physical and chemical characteristics. Carbon nanotubes have been widely studied due to their potential applications in many fields including conductive and high-strength composites, energy storage and energy conversion devices, sensors, field emission displays and radiation sources, hydrogen storage media, and nanometer-sized semiconductor devices, probes, and quantum wires. Some of these applications have been realized in products, while others show great potentials. The development of carbon nanotubes-based sensors has attracted intensive interest in the last several years because of their excellent sensing properties such as high selectivity and prompt response. Carbon nanotube-based gas sensors are summarized in this paper. Sensors based on single-walled, multiwalled, and well-aligned carbon nanotubes arrays are introduced. Modification of carbon nanotubes with functional groups, metals, oxides, polymers, or doping carbon nanotubes with other elements to enhance the response and selectivity of the sensors is also discussed.

Copyright ( 2009 W.-D. Zhang and W.-H. Zhang. This is an open access article distributed under the Creative Commons Attribution License, which permits unrestricted use, distribution, and reproduction in any medium, provided the original work is properly cited.

\section{Introduction}

Carbon nanotubes (CNTs) are a group of one-dimensional nanoscale materials composed of carbon atoms with fullerene structure, in which each carbon atom is $\mathrm{sp}^{2}$ hybrid and every carbon atom is covalently bonded to another three adjacent carbon atoms. According to the number of their wall layer, they can be single-walled carbon nanotubes (SWCNTs) and multiwalled carbon nanotubes (MWCNTs). A single-walled carbon nanotube can be considered as being formed by rolling a piece of graphene to create a seamless cylinder with diameters of $0.4-2 \mathrm{~nm}$. MWCNT comprise of several layers of graphene cylinders that are concentrically nested like rings of a tree trunk, with an interlayer distance close to that of graphite $(0.34 \mathrm{~nm})$. Both MWCNTs and SWCNTs have diameters in the range between fractions of nanometers and tens of nanometers and length up to several centimeters with both their ends normally capped by fullerene-like structures [1]. Three main methods being developed for CNTs synthesis are arc-discharge, laser ablation, and chemical vapor deposition (CVD) [2]. Since the discovery of MWCNTs [3] in 1991 and the SWCNTs in 1993 [4], CNTs have attracted extensive research interest due to their outstanding structural, electronic, and mechanical properties such as unique tubular structure like fullerene, high chemical and thermal stability, low weight, high electrical conductivity, stability, good heat conductance, large surface area, flexibility, high elasticity, and, high mechanical strength. CNTs play very important role in nanotechnology which greatly influences many different disciplines involving biology, chemistry, physics, medicine, engineering, electronics and material science [5].

The electronic property of SWCNTs is determined by their size and chirality. The SWCNTs can be metallic or semiconductive. The conductivity of each layer of MWCNTs behaves like an SWCNT along the axial direction, while it is very poor between the layers. As a whole, most MWCNTs display good conductivity. The unique electronic property combining with others makes carbon nanotubes ideal building block for electronic devices such as quantum wires, diodes, field-effect transistors (FETs), sensors, and cold cathode field emitters [1].

Carbon nanotubes are attractive for the task of chemical sensors, especially for nanoscale gas sensors. The development of CNTs-based gas sensors has attracted intensive interest in the last several years because of their high response, 
prompt response, low power consumption, small size and low operating temperature. The fabrication, structure and gas-sensing characteristics of CNTs-based gas sensors are reviewed in this paper and the challenge and strategic consideration for future development are also discussed. Gas sensors based on pristine CNTs including SWCNTs, MWCNTs and aligned CNTs are introduced, and the modification of CNTs with functional groups, metals, metal oxides and polymers for gas sensors are also discussed.

Most of the CNT sensors are based on FET devices with a semiconductive single nanotube (Figure 1(a)) or nanotube networks (Figure 1(b)) as the active sensing elements, and the conductivity of the CNTs was monitored when the sensors were exposed to various atmospheres.

\section{Gas Sensors Based on Pristine Carbon Nanotubes}

2.1. Gas Sensors Based on SWCNTs. It has been reported that SWCNTs are sensitive to $\mathrm{NO}_{2}, \mathrm{NH}_{3}$ and volatile organic compounds. The adsorption of gaseous molecules either donates or withdraws electron from the SWCNTs, leading to changes of electrical properties of the SWCNTs [6]. The high and fast response of the SWCNTs gas sensors has been assured. The drawback of these sensors is slow and incomplete recovery. To date, there have been a variety of attempts to overcome this limitation.

Kong et al. demonstrated the potential of CNT-based gas sensors when they reported the response of fieldeffect transistor (FET) devices to $\mathrm{NO}_{2}$ and $\mathrm{NH}_{3}$ [7]. The FET devices, utilizing a single semiconductive SWCNT (SSWCNT) as the conduction channel, showed a unique response to $\mathrm{NH}_{3}$ and $\mathrm{NO}_{2}$ through chemical gating of the SWCNT. The response time of the devices to $200 \mathrm{ppm}$ $\mathrm{NO}_{2}$ was a few seconds, and the response (defined as the ratio between resistance after and before gas exposure) was approximately 100-1000. Recovery was slow at room temperature (ca. 12 hours), but decreased to approximately 1 hour upon heating. The response time to approximately $1 \% \mathrm{NH}_{3}$ was a few minutes with the response between 10 and 100. An individual nanotube sensor can be used to detect different types of molecules. The selectivity is achieved by adjusting the electrical gate to set the $\mathrm{S}$ SWCNT sample in an initial conducting or insulating state. However, the mechanism causing the response of the FET based on single CNT remains unclear. Three models have been proposed to explain it. The first is charge transfer between the nanotube and the molecules adsorbed on its surface. The second is molecular gating of the CNT by the polar molecules such as $\mathrm{NO}_{2}$, which results in shift of the gate threshold of the semiconducting SWCNT. The third is a change in the Schottky barriers between the nanotube and the electrodes [8, 9]. Peng et al. studied the adsorption, diffusion, and reaction of $\mathrm{NO}_{2}$ on a SWCNT using ab initio simulations [10]. Since there are catalyst islands on SWCNT, and $\mathrm{NO}_{2}$ molecules are known to interact with catalytic surfaces to form $\mathrm{NO}$ and $\mathrm{NO}_{3}$ molecules, a chemical reaction may occur as follows:

$$
\mathrm{NO}_{2}+\mathrm{NO}_{2} \longrightarrow \mathrm{NO}+\mathrm{NO}_{3}
$$

On the equilibrium, the desorption of $\mathrm{NO}_{2}$ and $\mathrm{NO}$ molecules is very fast (less than 1 second at room temperature), while the desorption of $\mathrm{NO}_{3}$ molecules is much slower (about 12 hours). From the fact that $\mathrm{NO}_{3}$ is the major concentration on the SWCNT surface, and its recovery time will accordingly determine the recovery time of the overall SWCNT system, they deduced that it is $\mathrm{NO}_{3}$ that is responsible for the slow recovery.

The different recovery rate can be interpreted in terms of the desorption energy barrier of gas molecules on the CNT. For FET devices, the desorption energy barrier for adsorbed dimethyl methylphosphonate [11], $\mathrm{NH}_{3}$ [12], or $\mathrm{NO}_{x}$ [13] molecules on SWCNT could be reduced under positive gate voltages. A negative gate bias bends the energy band of the CNT upwards. Due to a thin barrier width, holes could tunnel through the barrier and enter the CNT channel easily. When a positive gate bias is applied, the CNT's energy band is bent downwards and hole tunneling is suppressed. A positive gate bias can promote fast recovery, which suggests that room temperature reversible CNT sensors for dimethyl methylphosphonate or $\mathrm{NH}_{3}$ are feasible.

By simply casting of SWCNTs on an interdigitated electrode, Li et al. [14] fabricated a gas sensor for detection of gases and organic vapors at room temperature. The sensor responses are linear for concentrations of sub ppm to hundreds of ppm with detection limit of $44 \mathrm{ppb}$ for $\mathrm{NO}_{2}$ and $262 \mathrm{ppb}$ for nitrotoluene. The recovery time was very long, on the order of 10 hours because of the higher bonding energy between SWNTs and $\mathrm{NO}_{2}$. By using ultraviolet (UV) light to knock the adsorbed molecules out of the SWCNT sites, the recovery time was shortened to about 10 minutes. The UV exposure decreases the desorption-energy barrier to ease the $\mathrm{NO}_{2}$ desorption. Under UV illumination, oxygen photodesorption causes a reduction of the hole carriers in the SWCNT, thus lowering the conductance of the sample. In air, gradual oxygen readsorption onto the nanotube upon turning off the light leads to the recovery of sample conductance [15].

Efforts have also been made to improve gas desorption by heating the sensors and increasing the flux rate of carrier gas. Quang et al. fabricated sensors from SWCNTs by a screen-printing method [16]. These sensors have been exposed to $\mathrm{NH}_{3}$ gas at room temperature with nitrogen as the carrier gas. The SWCNTs are very sensitive to $\mathrm{NH}_{3}$ and can detect $\mathrm{NH}_{3}$ with low concentration of $5 \mathrm{ppm}$ with a response time of 10 minutes. When the sensor is exposed to $\mathrm{NH}_{3}$, electrons are transferred from $\mathrm{NH}_{3}$ to SWCNTs. $\mathrm{NH}_{3}$ donates electrons to the valence band of the carbon nanotubes, decreasing the number of holes, thereby increasing the separation between the Fermi level and the valence band. This forms a space charge region at the surface of the semiconducting SWCNTs, which increases 


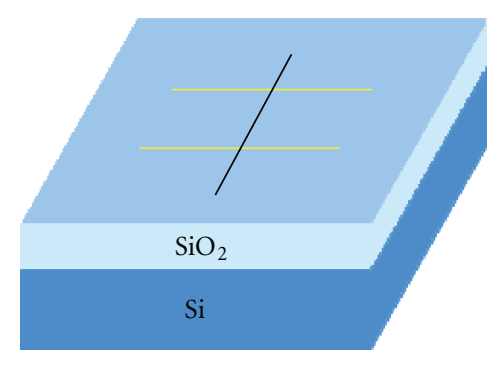

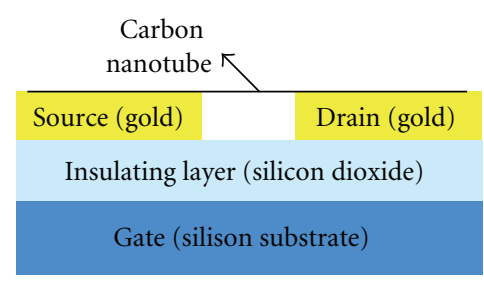

(a)

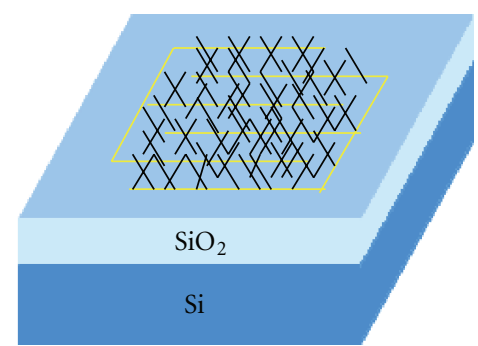

(b)

FIGURE 1: Schematic diagrams of (a) a gas sensor based on FET with a single carbon nanotube as sensing element, and (b) a resistive gas sensor with CNT bundles or thin film as sensing element.

the electrical resistance. A saturation state is established at a concentration of about $40 \mathrm{ppm}$, and the response of the sensor continues to increase in conjunction with an increase in concentration levels. The sensor completely recovers to its initial state at $80^{\circ} \mathrm{C}$ and under $1000 \mathrm{sccm} \mathrm{N}_{2}$ flux. Nguyen et al. also constructed sensors from SWCNT powders by screen-printing, followed by annealing pretreatment in open-air for 2 hours at various temperatures to enhance the sensor characteristics [17]. The sensor annealed at $200^{\circ} \mathrm{C}$ was employed for detection of $\mathrm{NH}_{3}$ with $500 \mathrm{sccm}$ $\mathrm{N}_{2}$ flowing. After being exposed to $5 \mathrm{ppm} \mathrm{NH}_{3}$ for 10 minutes at room temperature, the resistance of the sensor increased up to $8 \%$ in comparison with its initial value. The strong bonding between $\mathrm{NH}_{3}$ molecules and the SWCNTs requires a long time to degas and it causes the slow recovery of the SWCNT-based sensor. The carrier gas flux was intensified in desorption time to remove the adsorbed $\mathrm{NH}_{3}$ molecules from the SWCNTs. The stronger carrier gas flux was conducted, the better recovery the sensor exhibited. The behavior of the SWCNT shows a transition from semiconducting at a moderate temperature $\left(<350^{\circ} \mathrm{C}\right)$ to metallic at high temperature $\left(>350^{\circ} \mathrm{C}\right)$, which suggested that the heating treatment might cause a structural change in the SWCNT, leading to a change in its chirality. Heating at a moderate temperature could reduce the resistance of the sensor, therefore degrading response in detection of $\mathrm{NH}_{3}$. In order to avoid this problem, heating was not applied in sensing duration but in desorption time, for only 5 minutes at $70^{\circ} \mathrm{C}$. In addition, the carrier gas flux was maximized to $1000 \mathrm{sccm}$ for degassing. In summary, by increasing the carrier gas flux, combined with heating at $70^{\circ} \mathrm{C}$, the sensor recovery was dramatically improved. All these methods improved partly the recovery of the SWCNTs-based sensors, but the recovery time is still not satisfactory.
According to the thermodynamics, the adsorption or desorption rate of gas molecules on solid surface could be expressed as follows:

$$
\begin{aligned}
& r_{a}=K f(\theta) \exp \left(-\frac{E_{a}}{R T}\right), \\
& r_{d}=K^{\prime} f^{\prime}(\theta) \exp \left(-\frac{E_{d}}{R T}\right),
\end{aligned}
$$

where $r_{a}$ and $r_{d}$ are the rate of adsorption and desorption, respectively; $E_{a}$ and $E_{d}$ are the activation energy of adsorption and desorption, respectively; $T$ is the temperature; $K$ and $K^{\prime}$ are the adsorption or desorption rate constant. $\theta$ is the fraction of the surface occupancy. $f(\theta)$ is a function related to surface vacancy $(1-\theta), f^{\prime}(\theta)$ is a function related to generally written to be related to surface occupancy $(\theta)$. Based on the above equations, $r_{a}$ increases with the increasing of the gaseous pressure and fraction of the surface vacancy and reduces with the increasing of the adsorption activation energy. $r_{d}$ increases with the increasing of the desorption temperature and fraction of the surface covered and reduces with the increasing of the desorption activation energy. As a result, heating is favorable for desorption, thus enhancing the recovery of the sensors. On the other hand, irradiation with UV light reduces the desorption activation energy, which is plausible for recovery of the gas sensors also.

2.2. Gas Sensors Based on MWCNTs. So far, it has been reported that MWCNTs are sensitive to a variety of gases such as $\mathrm{NH}_{3}, \mathrm{NO}, \mathrm{NO}_{2}, \mathrm{H}_{2}, \mathrm{SF}_{6}$, and $\mathrm{Cl}_{2}$. The main drawback of MWCNTs gas sensors is also the slow recovery. For example, Varghese et al. [18] investigated two sensor geometries, one capacitive with MWCNT-SiO ${ }_{2}$ composite placed over a planar interdigital capacitor, the other resistive with MWCNTs 
grown upon a serpentine $\mathrm{SiO}_{2}$ pattern. Reversible behavior is demonstrated for the MWCNTs sensors in response to humidity, $\mathrm{CO}$ and $\mathrm{CO}_{2}$. The response time of both sensors to $\mathrm{NH}_{3}$ was approximately 2-3 minutes but it took the sensor several days in vacuum at $100^{\circ} \mathrm{C}$ to recover the original response. The impedance changes are attributed to p-type conductivity in semiconducting MWCNTs, and the formation of Schottky barriers between the metallic and semiconducting nanotubes. Of the sensors tested, the interdigital capacitor showed higher response. Nguyen et al. [19] developed a device with interdigital Pt electrodes on an $\mathrm{Al}_{2} \mathrm{O}_{3}$ substrate in order to evaluate the MWCNTs-based gas sensor capabilities. The MWCNT films were found to exhibit a fast response and a high response to $\mathrm{NH}_{3}$ at room temperature. The response $\left(S=\left(R_{0}-R\right) / R_{0}\right.$, where $R_{0}$ represents the resistance in dry air and $R$ is the resistance in the $\mathrm{NH}_{3}$ gas environment), varies from $75 \%$ to $85 \%$ when the gas concentration increases from 2500 to $7500 \mathrm{ppm}$. This change is due to the electron transfer from gas molecules to the nanotubes, leading to decrease of the resistance of the CNTs film. Moon et al. [20] fabricated the sensor employing MWCNTs as an active sensing element by using screenprinting method, and the sensor returned to the initial conductance employing a bias voltage for detecting $\mathrm{NO}_{2}$. The response $\left(S=G_{g} / G_{0}\right.$, where $G_{0}$ is the initial conductance of the sensor and $G_{g}$ is the conductance of nanotube films being exposed to $\mathrm{NO}_{2}$ ) to $50 \mathrm{ppm} \mathrm{NO}_{2}$ was approximately $22.7 \%$. In a vacuum state, the sensor conductance was refreshed using a CNT-bias-heating method. The recovery was maintained for 10 minutes with bias voltage of $10 \mathrm{~V}$, and the heating value was $28.8 \mathrm{cal}$. The recovery time decreased when the degassing energy was provided all at once, more than the divided heating. MWCNT films in the sensor could be used as a heater with a bias voltage, and the recovery time could be controlled by a bias voltage. The temperature variation was dependent on the bias voltage and the possible high electrical current. Gas desorption is affected by heating value which is controlled by time and bias voltage. The recovery time decreased upon an increase of bias voltage.

Suehiro et al. [21] demonstrated the partial discharge detection in $\mathrm{SF}_{6}$ gas using an MWCNTs-based gas sensor. The sensor was fabricated by positive dielectrophoresis of MWCNTs on a microelectrode array. The sensor can detect main decomposition products such as $\mathrm{SO}_{2}$ or $\mathrm{HF}$ at ppm level. When the partial discharge was generated, the electrical conductance of the MWCNT sensor gradually increased. The sensor response was reversible and was influenced by both the partial discharge intensity and the relative position of the sensor to the point electrode. The increase of the sensor conductance was caused by an electronic interaction between MWCNTs and nonidentified oxidative decomposition products. The sensor could realize a real-time detection of faint partial discharge activities that detection tubes could not sense.

An electrochemical gas sensor modified with MWCNTs film as electrocatalyst for the determination of $\mathrm{Cl}_{2}$ has also been constructed [22]. $\mathrm{Cl}_{2}$ gas was allowed through the cathode surface of the sensor, and the resulting galvanic effects were monitored. This amperometric gas sensor showed excellent response, high stability, and fast recovery for the determination of $\mathrm{Cl}_{2}$ in $\mathrm{H}_{2} \mathrm{SO}_{4}$. In the plateau potential region, the reduction of $\mathrm{Cl}_{2}$ is controlled with the mass transfer of $\mathrm{Cl}_{2}$ through the working electrode. Therefore, the limiting current produced in this region can be used to quantify the $\mathrm{Cl}_{2}$ concentration. When using nanotube-based microelectrode, the electrode has a porous structure and is probably well wetted by the solvent/electrolyte medium [23]. The performance of the electrochemical sensor for $\mathrm{Cl}_{2}$ with MWCNTs as electrocatalyst was stable and it was not interfered by the redox gases, such as $\mathrm{CO}, \mathrm{NO}, \mathrm{O}_{2}, \mathrm{CO}_{2}$, and $\mathrm{C}_{3} \mathrm{H}_{8} \cdot \mathrm{CO}_{2}$ is an inert gas, so it is difficult to react on the surface of MWCNTs-modified electrode. The response and recovery time of this sensor is about 150 seconds. The response time for MWCNTs is prolonged to about 150 seconds due to the small proportion of exposed edge plane.

As mensioned before, SWCNTs consist of single graphite sheets, while MWCNTs comprise an array of nanotubes that are concentrically nested. Depending on their chirality and diameter, an SWCNT can be either metallic or semiconducting. In practice, it is difficult to obtain only semiconducting nanotubes from grown samples, which are usually mixtures of both metallic and semiconducting SWCNTs [24]. Suehiro et al. [25] demonstrated that the normalized response of the SWCNT sensor was higher than that of the MWCNT sensor. Probably it is because SWCNTs contained more semiconducting tubes. In general, MWCNTs show a conducting (metallic) behavior at room temperature. However, MWCNTs could contain some semiconducting tubes among predominantly metallic ones. The higher normalized response of the SWCNT sensor may be attributed to higher abundance of the semiconducting tube, which is responsible for the sensor response.

2.3. Gas Sensors Based on Well-Aligned CNTs. It has been reported that aligned CNTs (ACNTs) are sensitive to $\mathrm{NO}_{2}$, $\mathrm{NH}_{3}$ and $\mathrm{H}_{2}$. For example, Valentini et al. [26] prepared aligned CNT thin films by pulsed plasma chemical vapor deposition system for the detection of $\mathrm{NO}_{2}$. The sensors exhibited fast and high response at room temperature and could detect as low as $10 \mathrm{ppb} \mathrm{NO}_{2}$ at $165^{\circ} \mathrm{C}$ with fast recovery. The resistance of CNTs films decreased while contacting with $\mathrm{NO}_{2}$, whereas it increased with $\mathrm{NH}_{3}$, ethanol, humidity, and $\mathrm{C}_{6} \mathrm{H}_{6}$. The CNT film can be viewed as an aligned network of CNTs somewhere connected with CNT/CNT junctions. The crossed junctions between CNTs act as a gate for carriers to move in the film, and they may consist either in directly cross-linked defective nanotubes or in amorphous carbon impurities. Therefore the CNT film can be represented as a network of effective resistors formed by the resistance of the nanotube body, the resistance of the junctions, and the tunnelling resistance due to tubetube electronic coupling between adjacent but not connected nanotubes. At $165^{\circ} \mathrm{C}, \mathrm{NO}_{2}$ is favored to decompose $\mathrm{O}_{2}$ molecules in the air, generating atomic oxygen which preferentially attacks the defective sites of the CNT, thus produced volatile species like $\mathrm{CO}$ and $\mathrm{CO}_{2}$ with the consumption of the defective sites. Moreover, amorphous carbon impurities 
were also oxidized in such conditions, thus decreased the number of metallic like (Fermi) junctions. Cho et al. [27] fabricated a sensor by using selectively grown MWCNTs as the sensing element on a substrate of a stacked microheater structure with a $\mathrm{Cr}$ heater and a diaphragm to improve the recovery time and response of the MWCNTs films. To offer more reaction area between MWCNTs and $\mathrm{NO}_{2}$ molecules, MWCNTs' films with mesh and serpentine shapes were fabricated. It took about 6 hours for the sensor to return to the initial resistance at room temperature. The MWCNTs thin films can be better recovered only by properly selecting the thermal treatment protocols. The change of the resistance of the mesh-shaped MWCNTs films to $\mathrm{NO}_{2}$ was found to be larger than that of the serpentine-shaped MWCNTs films because the number of reaction areas between MWCNTs and $\mathrm{NO}_{2}$ molecules was increased. Ueda et al. [28] prepared wellaligned CNTs on Si substrate by thermal CVD. The resistance of the sensor decreased with an increase of ambient $\mathrm{NO}$ and $\mathrm{NO}_{2}$ gas concentration. The CNTs thin film can be applicable to an $\mathrm{NO}_{x}$ gas sensor. The changing rate of the resistance of the sensor was proportional to the concentration of the target gas. UV light irradiation can reset the resistance of the CNTs sensor by photodetachment of adsorbed molecules at room temperature. Hoa et al. [29] developed a vertical transport type CNTs-based $\mathrm{NH}_{3}$ gas sensor structure. The structure features regular arrays of CNTs with uniform diameter and length, but the nanotubes also have high defect levels. The sensor shows high response, fast response time of less than 1 minute and good reproducible recovery behavior in atmospheric pressure with the forward biases of $5 \mathrm{~V}$ at room temperature due to the high defect density, and could detect $\mathrm{NH}_{3}$ at the range of $0.1-6 \%$. The CNTs with a higher defect density revealed better response. The oxygenation degrades the response to $\mathrm{NH}_{3}$, but the crystallographic defects can enhance it in the CNT sensors. The recovery time is not sensitive to the gas concentration, which may be due to the forced desorption of the $\mathrm{NH}_{3}$ molecules by the refreshing nitrogen flow. Figure 2 shows the schematics of sensor fabrication process and switching of the sensor measured at different $\mathrm{NH}_{3}$ concentration. The regularity of the CNTs in diameter and length was a great help in clearly defining the senors' specification and in realizing sensor-tosensor uniformity.

$\mathrm{N}_{2}$ absorption characteristics of the vertically aligned CNTs-based three-terminal gas sensor at room temperature were also studied [30]. Upon exposure to $\mathrm{N}_{2}$ (filling pressure from 50 mTorr to 500 Torr) and without $\mathrm{N}_{2}$ at $10 \mathrm{~V}$ bias voltage, the electrical resistance of the as-made devices was found to increase and to return back, respectively. Compared to a low bias, a high drain-source voltage enhanced the response for monitoring $\mathrm{N}_{2}$ gas. $\mathrm{N}_{2}$, owning higher adsorption energy, was easier to absorb by CNTs than Ar. The response was further improved by applying a negative gate voltage owing to the addition of conducting holes to the CNTs mat.

The response of multifinger with aligned SWCNT is double with respect to disordered SWCNT [31]. This effect is probably induced by the fact that the ordered SWCNTs are more uniformly exposed to the $\mathrm{NH}_{3}$ molecules, than the case of placement of SWCNTs in form of a random network, in which part of the SWCNT remains inaccessible to the gas molecules.

Gas-sensing performance of pristine CNT sensors is summarized in Table 1.

\section{Gas Sensors Based on Modified Carbon Nanotubes}

3.1. Gas Sensors Based on CNTs with Functional Groups. Modification of CNTs with functional groups, metal nanoparticles, oxides, and polymers will change the electronic properties of them, and enhancing the selectivity and response to specific gases though the interaction of the target molecules with the functional groups or additives is very different. Most of the previous reports are based on utilization of carboxylic acid $(-\mathrm{COOH})$ group, which provides reactive sites for interacting with different reactive compounds, at the ends and side-walls of the CNTs. Hsu et al. [32] reported that the $-\mathrm{COOH}$ group grafted on MWCNTs provides reactive sites via esterification or elimination, and the MWCNTs retain the graphitic structure. The HCl-treated MWCNTs were efficiently oxidized with nitric acid/hydrogen peroxide $(\mathrm{v} / \mathrm{v}=2 / 1)$ solution to generate $-\mathrm{COOH}$ group on the defect sites of MWCNTs. The surface acoustic wave (SAW) crystal sensor coated with MWCNT-COOH/poly(n,n-dimethylamino propylsilsesquioxane) exhibited a high response for ethanol vapor efficiently. Mäklin et al. [33] demonstrated NO gas sensing with carboxyl functionalized SWCNTs and MWCNTs. When exposed to NO, the conductivity of the sensors changed up to about $40 \%$ for SWCNTs and $12 \%$ for MWCNTs; however, the response was found to be fairly independent on NO concentration. Sensors made of SWCNTs outperform their counterparts with MWCNTs, which is a sign of tunable Fermi level in the semiconducting nanotubes. Recently, Fu et al. [34] demonstrated experimentally that sensors made of carboxylated SWCNTs were sensitive to $\mathrm{CO}$, with a lower detection limit of $1 \mathrm{ppm}$, whereas pristine SWCNTs did not respond. The authors exploited the different responses of carboxylated and pristine SWCNTs to differentiate between $\mathrm{CO}, \mathrm{NO}$, and $\mathrm{NO}_{2}$. The $\mathrm{COOH}$ functionality is crucial to the $\mathrm{CO}$ sensing, and the $\mathrm{CO}$ molecules can be absorbed on carboxylic acid functionalities through weak hydrogen bonding.

Tran et al. [35] investigated the effect of $-\mathrm{NH}_{2}$ functionalized $\mathrm{SiO}_{2}$ surface on the gas sensing properties of SWCNTs modified with 3-aminopropyltriethoxysilane (APTES). The relative resistance change of the SWCNTs to $\mathrm{NO}_{2}$ in the case of the APTES-treated surface was twice larger than the case without surface treatment under the same conditions. The surface treatment by the SWCNTs did not affect the recovery time of the gas sensor. A significantly fast response time of the sensor with the SWCNTs treatment was observed when exposed to $10 \mathrm{ppm}$ or $50 \mathrm{ppm} \mathrm{NO}_{2}$. The amine groups in the APTES monolayer, electron donating in nature, played a role of charge transfer to the semiconducting SWCNTs, and hence the amount of electrons transferred from SWCNTs to $\mathrm{NO}_{2}$ molecules increased. 


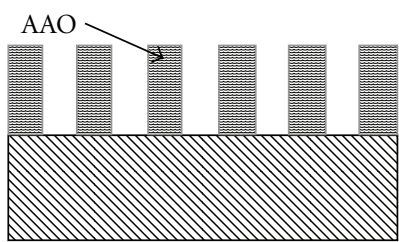

(a) AAO fabrication

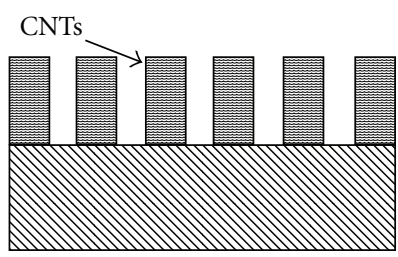

(c) Open the CNTs

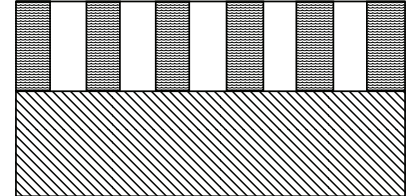

(b) Synthesis of CNTs

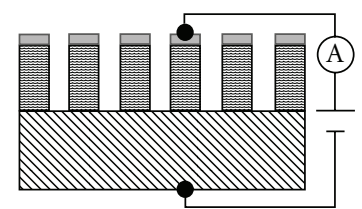

(d) Deposit Ag electrode

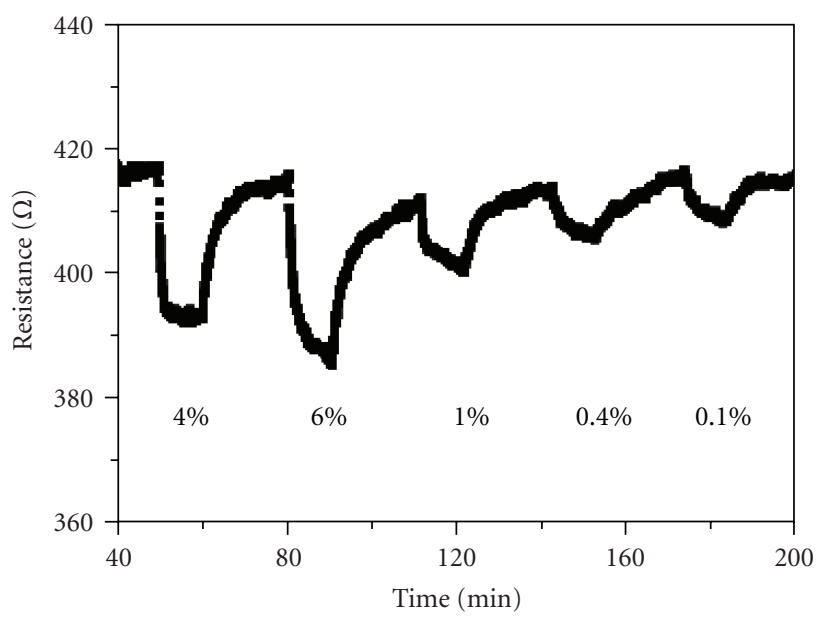

(e)

FIGURE 2: Schematics of sensor fabrication process. (a) Synthesis of anodic aluminum oxide (AAO) on p-type Si substrate, (b) synthesis of CNTs by thermal CVD, (c) removal of the top carbon layer by oxygen plasma, (d) Ag electrode deposition and (e) switching of the sensor measured at different $\mathrm{NH}_{3}$ concentrations. Reprinted with permission [29].

TABLE 1: Summary of gas-sensing performance of pristine CNT gas sensors. (Note: N/S = Not-stated.)

\begin{tabular}{|c|c|c|c|c|c|c|}
\hline CNT type & $\begin{array}{l}\text { Sensor } \\
\text { configuration }\end{array}$ & Targeted analytes & Detection limit & Response time & Recovery time & Reference \\
\hline S-SWCNT & FET & $\mathrm{NO}_{2}, \mathrm{NH}_{3}$ & $\begin{array}{l}2 \mathrm{ppm} \mathrm{NO} \mathrm{NO}_{2}, \\
0.1 \% \mathrm{NH}_{3}\end{array}$ & $<10 \min$ & $\sim 1 \mathrm{~h}\left(200^{\circ} \mathrm{C}\right)$ & [7] \\
\hline SWCNTs & Resistor & $\mathrm{NO}_{2}$, Nitrotoluene & $\begin{array}{l}44 \mathrm{ppb} \mathrm{NO}, \\
262 \mathrm{ppb} \\
\text { Nitrotoluene }\end{array}$ & $10 \mathrm{~min}$ & $10 \min (\mathrm{UV})$ & {$[14]$} \\
\hline SWCNTs & Resistor & $\mathrm{NH}_{3}$ & $5 \mathrm{ppm}$ & $\sim 10 \mathrm{~min}$ & $\sim 20 \min \left(80^{\circ} \mathrm{C}\right)$ & {$[16]$} \\
\hline SWCNTs & Resistor & $\mathrm{NH}_{3}$ & $5 \mathrm{ppm}$ & $\sim 10 \mathrm{~min}$ & $\sim 10 \min \left(70^{\circ} \mathrm{C}\right)$ & {$[17]$} \\
\hline MWCNTs & $\begin{array}{l}\text { Capacitor and } \\
\text { Resistor }\end{array}$ & $\mathrm{NH}_{3}$ & $10 \mathrm{ppm}$ & $2-3 \min$ & $\begin{array}{l}\text { several days } \\
\left(100^{\circ} \mathrm{C} \text { in }\right. \\
\text { vacuum })\end{array}$ & {$[18]$} \\
\hline MWCNTs & Resistor & $\mathrm{NH}_{3}$ & $2500 \mathrm{ppm}$ & $\mathrm{N} / \mathrm{S}$ & $\mathrm{N} / \mathrm{S}$ & {$[19]$} \\
\hline MWCNTs & FET & $\mathrm{NO}_{2}$ & $50 \mathrm{ppm}$ & $\sim 500 \mathrm{~s}$ & $\begin{array}{l}\sim 10 \min (10 \mathrm{~V} \\
\text { bias potential) }\end{array}$ & {$[20]$} \\
\hline MWCNTs & Resistor & $\mathrm{SO}_{2}, \mathrm{HF}$ & $\begin{array}{l}10 \mathrm{ppm} \mathrm{SO}_{2}, \\
4 \mathrm{ppm} \mathrm{HF}\end{array}$ & $\mathrm{N} / \mathrm{S}$ & $\mathrm{N} / \mathrm{S}$ & {$[21]$} \\
\hline MWCNTs & $\begin{array}{l}\text { Electrochemical } \\
\text { Gas sensor }\end{array}$ & $\mathrm{Cl}_{2}$ & 100 ppm & $\sim 150 \mathrm{~s}$ & $\sim 150 \mathrm{~s}$ & {$[22]$} \\
\hline ACNTs & Resistor & $\mathrm{NO}_{2}$ & $10 \mathrm{ppb}$ & $\sim 60 \mathrm{~min}$ & $\sim 60 \min \left(165^{\circ} \mathrm{C}\right)$ & {$[26]$} \\
\hline ACNTs & Resistor & $\mathrm{NO}_{2}$ & 10 ppm & $\mathrm{N} / \mathrm{S}$ & $\mathrm{N} / \mathrm{S}$ & [27] \\
\hline ACNTs & Resistor & $\mathrm{NO}, \mathrm{NO}_{2}$ & $\begin{array}{l}2 \mathrm{ppm} \mathrm{NO} \\
2 \mathrm{ppm} \mathrm{NO}_{2}\end{array}$ & $\mathrm{~N} / \mathrm{S}$ & $\begin{array}{l}\sim 20 \mathrm{~min}\left(150^{\circ} \mathrm{C}\right. \\
\text { and } \mathrm{UV})\end{array}$ & {$[28]$} \\
\hline ACNTs & Resistor & $\mathrm{NH}_{3}$ & $\sim 0.1 \%$ & $\mathrm{~N} / \mathrm{S}$ & $\mathrm{N} / \mathrm{S}$ & [29] \\
\hline ACNTs & FET & $\mathrm{N}_{2}$ & 50 mTorr & $\mathrm{N} / \mathrm{S}$ & $\mathrm{N} / \mathrm{S}$ & {$[30]$} \\
\hline
\end{tabular}

3.2. Gas Sensors Based on Polymer Functionalized CNTs. Among the organic polymers, conducting polymers are the most promising materials for gas sensing as they have delocalized bonds that make them semiconducting or even highly conductive. Several conducting polymers, for example, polyaniline, polypyrrole, polythiophene have been demonstrated to be good sensing materials to function at room temperature. They have been applied as conductometric, potentiometric, amperometric and voltammetric transducers for the detection of a wide variety of gas or vapors such as $\mathrm{NH}_{3}, \mathrm{NO}_{2}, \mathrm{CO}$ and VOCs. However, their selectivity and the environmental stability are poor. Recently, enhanced gas sensing by combining SWCNTs with organic polymers has been demonstrated. Qi et al. showed that 
noncovalently dropcoating of polyethyleneimine (PEI) and Nafion (a polymeric perfluorinated sulfonic acid ionomer) onto SWCNTs FETs resulted in gas sensors with improved response and selectivity for $\mathrm{NO}_{2}$ and $\mathrm{NH}_{3}$ [36]. The PEI functionalization changed the SWCNTs from p-type to ntype semiconductors, and the sensors based on PEI modified SWCNTs were able to detect less than $1 \mathrm{ppb} \mathrm{NO}_{2}$ with a response time of 1-2 minutes (defined as the time for $80 \%$ conductance change to take place) while being insensitive toward $\mathrm{NH}_{3}$. The conductance of the n-type multipletube devices decreased upon $\mathrm{NO}_{2}$ binding due to electron transfer to $\mathrm{NO}_{2}$ reducing the majority carriers in the nanotubes. This $\mathrm{NH}_{3}$ insensitivity is attributed to low binding affinity and sticking coefficient of $\mathrm{NH}_{3}$ on the electron-rich (due to high-density amines on PEI) n-type SWNTs. PEI functionalized SWNTs are highly selective to many other molecules including $\mathrm{CO}, \mathrm{CO}_{2}, \mathrm{CH}_{4}, \mathrm{H}_{2}$, and $\mathrm{O}_{2}$. The sensor recovery was done by desorbing $\mathrm{NO}_{2}$ with $\mathrm{UV}$ light illumination. Contrary to PEI-coated sensors, Nafion coated SWCNTs were insensitive to $\mathrm{NO}_{2}$ but exhibiting a good sensitivity toward $\mathrm{NH}_{3}$. Chemical functionalization of SWCNTs with covalently attached poly-(m-aminobenzene sulfonic acid) (PABS) has been demonstrated to have better sensing performance toward $\mathrm{NH}_{3}$ and $\mathrm{NO}_{2}$ than simply carboxylated SWCNTs. Bekyarova et al. reported that the SWCNTs-PABS devices showed significant sensitivity to 5 ppm $\mathrm{NH}_{3}$ owing to PABS deprotonation during $\mathrm{NH}_{3}$ exposure [37]. This deprotonation resulted in hole depletion from the SWCNTs and a reduction in the overall conductance of the SWCNTs-PABS system. Zhang et al. used SWCNTs-PABS devices to reach detection limits of $100 \mathrm{ppb}$ $\mathrm{NH}_{3}$ and $20 \mathrm{ppb} \mathrm{NO}_{2}$ with short response time and full recovery [38]. At $20-30^{\circ} \mathrm{C}$, SWCNTs-PABS sensors usually take several hours to regenerate after exposure to $\mathrm{NO}_{2}$ above $300 \mathrm{ppb}$. Sulfonic acid groups as dopants play an important role in balancing the charge distribution within the polymer, and they are especially attractive for introducing acid-base response. When PABS is exposed to $\mathrm{NH}_{3}$ or water vapor, the adsorbed molecules cause deprotonation of the polymer, which depletes hole carriers and thus resulting in an increased electrical resistance. In contrast, exposure to $\mathrm{NO}_{2}$ causes protonation of the polymer, which induces hole accumulation and results in a decreased resistance of the SWNT-PABS sensors. When the sensor is purged with reference gas, the process is reversed and the original electrical resistance is restored.

CNTs have also been incorporated into polymers to form nanocomposites, which are usually casted to thin films and serve as sensing elements. For example, polypyrrole (PPy) /SWCNTs nanocomposite-based gas sensors have been fabricated by using a chemical polymerization technique followed by spin-casting onto prepatterned electrodes [39]. The response of the nanocomposites was about ten times higher than that of $\mathrm{PPy}$ (the resistance changed about $6 \%$ at $200 \mathrm{ppm} \mathrm{NO}_{2}$ ). The response was recovered fully after about 2 hours in the first cycle. However, in the next cycles, not only the response was degraded, it was also not fully recovered. The SWCNT bundles could be nanodispersed, which may increase the specific surface area of the coated
PPy and thereby increase the response further. The recovery time could be shortened, particularly in the nanocomposite, by taking advantage of the Joule-heating effect. Liu et al. synthesize individual SWCNT/PPy composite nanocables based on nanotube FET [40]. A recovery in conductance was observed with nanotube/PPy nanocables upon further deposition of $\mathrm{PPy}$, which results from the conduction through the conducting PPy layer. Furthermore, these composite materials enhanced conductance upon $\mathrm{NO}_{2}$ exposure and reduced conductance upon $\mathrm{NH}_{3}$ exposure. The observed conductance suppression in nanotube/PPy nanocables may originate from several factors. The first is the formation of scattering centers close to the nanotube when PPy was deposited. The deposited PPy might form covalent bonds with the nanotube at the defect sites and subsequently lead to enhanced scattering. The PPy coating may significantly alter the Schottky barrier at the metal-nanotube contacts and contribute to the observed conductance suppression. Santhosh et al. developed an amperometric sensor based on polydiphenylamine (PDPA) grafted MWCNTs (MWNTg-PDPA) for determination of CO. Cyclic voltammetry is used to fabricate the modified electrode and to demonstrate the electroactivity of MWNT-g-PDPA-ME toward gaseous $\mathrm{CO}$. The sensor exhibited high response for oxidation of $\mathrm{CO}$ in a $0.5 \mathrm{M} \mathrm{HClO}_{4}$ solution [41]. The sensor showed excellent linear concentration range between 10 and 200 ppm (correlation coefficient $r=0.9941$ ) with a substantially low detection limit of $0.01 \mathrm{ppm}$. The response to $\mathrm{CO}$ was rather quick; time for $96 \%$ response and $98 \%$ recovery to $100 \mathrm{ppm} \mathrm{CO}$ was about 2 and 3 seconds, respectively. The oxidation of $\mathrm{CO}$ to $\mathrm{CO}_{2}$ occurred at the triple-phase boundary among the electrolyte, MWNT-g-PDPA-ME and CO. When the MWNT-g-PDPA-ME was coated with $0.5 \%$ Nafion, the interference from $\mathrm{NH}_{3}, \mathrm{CH}_{4}, \mathrm{C}_{3} \mathrm{H}_{8}$, and $\mathrm{N}_{2} \mathrm{O}$ $(500 \mathrm{ppm})$ was not detected at MWNT-g-PDPA-ME. The insignificant or noninterference from these gases is attributed to the solubility and dielectric properties of the gases at a fluorinated polymer. Long-term stability of the MWNT-gPDPA-ME was checked for 10 days, and no change in the sensing current was observed.

Modification of CNTs with polymers also improves their sensing properties toward vapors of organic compounds (VOCs). Abraham et al. developed a compact wireless gas sensor based on an MWCNTs/PMMA composite chemiresistor [42]. The composite film was made by ultrasonication of MWCNTs and PMMA (1: 4 by weight) for 2 hours in dichloromethane, and the chemiresistors were fabricated by dip-coating. The sensor shows fast response (2-5 seconds) and $10^{2}-10^{3}$ order increase in resistance upon exposure to dichloromethane, chloroform and acetone vapors. It returns to the initial level immediately after removing the gas. The sensing mechanism was explained by swelling of the polymer due to absorption of organic vapors into the PMMA and the charge transfer when polar organic vapors adsorb on the CNT surface. Solvents such as methanol, ethyl acetate and toluene, in which PMMA is insoluble or less soluble, also showed response. The polar nature of the solvents and the extent of interaction determine the response of the sensor. Methanol vapor which can form hydrogen 
bonding with the polar groups on the CNT surface showed the maximum response among the three. However, this mechanism can induce only a weak response. Hexane is not a good solvent for PMMA. Being nonpolar, it did not show any response. The poly(3-methylthiophene)/MWCNTs nanocomposite-based sensor was used to selectively discriminate between chloromethane and methane, as the sensor showed a high response to chloromethane, while no response was observed when exposed to methane or many other VOCs [43]. The response and recovery time of the sensor was about 60 seconds and 30-45 seconds, respectively. The sensing mechanism was proposed to be based on ionization potential of the analytes. The nanocomposite sensor does not respond to vapors of acetone, acetaldehyde, benzaldehyde, tetrahydrofuran, methanol and ethanol. Zhang et al. fabricated the conductive polymer composites by in situ polymerization of styrene (PS) in the presence of MWCNTs or solution mixing of polystyrene with MWCNTs, respectively [44]. Compared with the composites prepared by solution mixing, the ones by in situ polymerization show much higher response to organic vapors over a wide range of MWCNTs (5-15 wt.\%). Sorption of organic vapors into the polymeric phase of the composites leads to swelling of the matrix, expands the interparticulates' intervals and partially destroys the conductive networks. As a result, a drastic rise in resistivity of the materials is perceived. When the amount of MWCNT in the composites is low, tunneling effect contributes to conduction of the composites to a great extent besides the direct interfiller contacts. In the case of high MWCNT content, the excessive fillers inevitably resulted in aggregation of MWCNTs and broke the conducting paths. Only at certain optimized filler content, the conducting paths are mainly constructed by the bridged MWCNTs, which are easy to be broken down by the swelling of the matrix, and the vapor response reaches the maximum. The composites synthesized through polymerization-filling exhibit significant responsivity to those organic vapors which are good solvents for the matrix, like tetrahydrofuran (THF), benzene, toluene, cyclohexane, carbon tetrachloride, chloroform, ethyl acetate and diethyl ether within short time of exposure, but low in response to those nonsolvents, such as alcohol. The resistance can be quickly and completely recovered to its original value as soon as the sample is transferred into air. Niu et al. constructed a highly selective gas sensor by chemical modification of MWCNTs containing carboxyl groups (MWCNT-COOH) with poly(ethylene glycol) (PEG) in the presence of $\mathrm{N}, \mathrm{N}$-dicyclohexylcarbodiimide (DCC) [45]. The MWCNTs grafted PEG sensor displayed high chemical selectivity, fast response and good reproducibility/high stability to chloroform vapor at room temperature. The resistance of the sensing film drastically increased over $10^{7}$ within 1 second upon exposed to chloroform vapor. When it was transferred from the solvent vapor into dry air, the electrical resistance returned to the original value rapidly. This is attributed to the weak hydrogen bond interaction between chloroform vapor and polymers, which results in an abrupt adsorption of analyte molecules in a short time. The response of the MWNT-g-PEG system toward ethanoic acid and water is about $10^{2}$ and $10^{1}$ respectively, and only very small response to any other solvent vapors was observed, and the film did not respond basically against nonpolar solvent vapors, for example, n-hexane.

Vertically aligned carbon nanotubes have also been modified with polymers for gas sensors. Valentini et al. fabricated a gas sensor by selective growth of aligned CNTs on $\mathrm{Si}_{3} \mathrm{~N}_{4} / \mathrm{Si}$ substrates patterned by metallic platinum [46]. The sensor was presented for inorganic vapor detection at room temperature. Poly(o-anisidine) (POAS) deposition onto the CNTs device was shown to impart higher response to the sensor. Upon exposure to $\mathrm{HCl}$, the variation of the CNTs response is less than $4 \%$, while the POAS-coated CNTs devices offer a higher response of $28 \%$. The extended detection capability to inorganic vapors is attributed to direct charge transfer with electron hopping effects on intertube conductivity through physically adsorbed POAS between CNTs. Wei et al. developed novel multifunctional chemical sensors based on vertically aligned MWCNTs and polymer composites [47]. The sensors were fabricated by partially coating perpendicularly aligned MWCNTs with polymers, such as poly(vinyl acetate), polyisoprene, and then sputtering with gold electrodes. Rapid and reversible sensing of high concentrations of a variety of volatile organic solvents was demonstrated. The sensing mechanism was attributed to the charge transfer interaction with gas molecules and/or the intertube distance change induced by polymer swelling during gas adsorption.

Gas-sensing performance of polymer functionalized CNT gas sensors is summarized in Table 2 .

\subsection{Gas Sensors Based on Metal Nanoparticles Modified CNTs.} Metals exhibit a broad range of electronic, chemical and physical properties that are often highly sensitive to changes in their chemical environment [48]. They are mechanically and chemically robust and stable, hence, compared to polymer-based sensors, metal-based sensors can operate at higher temperature and in harsher environment.

Palladium is one of the most important metal catalysts for activation of small molecules such as $\mathrm{H}_{2}$. It is also used as active component in gas sensors, including CNTs-based gas sensors. Kong et al. demonstrated room temperature $\mathrm{H}_{2}$ sensors based on Pd nanoparticles modified SWCNTs prepared by electron-beam evaporation deposition [49]. Pdfunctionalized SWCNTs were shown to be highly sensitive toward $\mathrm{H}_{2}$, with $50 \%$ greater response of up to $50 \%$ relative resistance change to $400 \mathrm{ppm} \mathrm{H}_{2}$ compared to bare SWCNT bundles. The response time was $5-10$ seconds, and the time for recovery was about 400 seconds. It is well established that at room temperature, the adsorbed $\mathrm{H}_{2}$ molecules on the surface of Pd nanoparticles are dissociated as hydrogen atoms, which dissolve into Pd with high solubility, leading to a decrease in the work function of Pd. This causes electron transfer from Pd to SWCNT and reduces the hole-carriers in the p-type SWCNT, and hence causes a decrease in conductance. The process is reversible as dissolved atomic hydrogen in $\mathrm{Pd}$ can combine with $\mathrm{O}_{2}$ in air to form $\mathrm{OH}$ which will further combine with atomic hydrogen to form water and then leave the Pd-SWCNT system, thus 
TABLE 2: Summary of sensing performance of polymer functionalized CNT sensors. (Note: N/S = Not-stated.)

\begin{tabular}{|c|c|c|c|c|c|c|c|}
\hline polymer & CNT type & $\begin{array}{l}\text { Sensor } \\
\text { configuration }\end{array}$ & Targeted analytes & Detection limit & Response time & Recovery time & Reference \\
\hline PEI, Nafion & SWCNTs & FET & $\mathrm{NO}_{2}, \mathrm{NH}_{3}$ & $100 \mathrm{ppb} \mathrm{NO}$ & $\sim 1-2 \mathrm{~min}$ & $\mathrm{~N} / \mathrm{S}$ & [36] \\
\hline PABS & SWCNTs & Resistor & $\mathrm{NH}_{3}, \mathrm{NO}_{2}, \mathrm{H}_{2} \mathrm{O}$ & 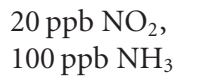 & $1-10 \mathrm{~min}$ & Several hours & [38] \\
\hline PPy & SWCNTs & FET & $\mathrm{NO}_{2}$ & $\mathrm{~N} / \mathrm{S}$ & $\mathrm{N} / \mathrm{S}$ & $\sim 2 \mathrm{~h}$ & [39] \\
\hline PPy & S-SWCNT & FET & $\mathrm{NO}_{2}, \mathrm{NH}_{3}$ & $\begin{array}{l}100 \mathrm{ppm} \mathrm{NO}_{2} \\
5 \mathrm{ppm} \mathrm{NH}\end{array}$ & $\mathrm{N} / \mathrm{S}$ & $\mathrm{N} / \mathrm{S}$ & {$[40]$} \\
\hline PDPA & MWCNTs & $\begin{array}{l}\text { Electrochemical } \\
\text { gas sensor }\end{array}$ & $\mathrm{CO}$ & $0.01 \mathrm{ppm}$ & $\sim 2 \mathrm{~s}$ & $\sim 3 \mathrm{~s}$ & [41] \\
\hline PMMA & MWCNTs & Resistor & $\begin{array}{l}\text { dichloromethane, } \\
\text { chloroform, } \\
\text { acetone }\end{array}$ & $\mathrm{N} / \mathrm{S}$ & $2-5 s$ & $\sim 10 \mathrm{~s}$ & {$[42]$} \\
\hline $\begin{array}{l}\text { Poly(3- } \\
\text { methylthiophene) }\end{array}$ & MWCNTs & Resistor & $\begin{array}{l}\mathrm{CH}_{2} \mathrm{Cl}_{2}, \mathrm{CHCl}_{3}, \\
\mathrm{CCl}_{4}, \mathrm{CH}_{4}\end{array}$ & $\mathrm{~N} / \mathrm{S}$ & $60 \mathrm{~s}$ & $30-45 s$ & {$[43]$} \\
\hline polystyrene & MWCNTs & Resistor & $\begin{array}{l}\text { the good solvents } \\
\text { of PS }\end{array}$ & $\mathrm{N} / \mathrm{S}$ & $<4 \min$ & $\sim 1 \mathrm{~min}$ & {$[44]$} \\
\hline PEG & MWCNTs & Resistor & chloroform & $\mathrm{N} / \mathrm{S}$ & $<1 \mathrm{~s}$ & $\mathrm{~N} / \mathrm{S}$ & {$[45]$} \\
\hline POAS & ACNTs & Resistor & $\mathrm{HCl}$ & $100 \mathrm{ppm}$ & $\mathrm{N} / \mathrm{S}$ & $\mathrm{N} / \mathrm{S}$ & [46] \\
\hline $\begin{array}{l}\text { poly(vinylacetate), } \\
\text { polyisoprene, etc. }\end{array}$ & ACNTs & Resistor & $\begin{array}{l}\text { Ethanol } \\
\text { cyclohexane, } \\
\text { tetrahydrofuran }\end{array}$ & $\mathrm{N} / \mathrm{S}$ & $<2 \min$ & $<2 \min$ & [47] \\
\hline
\end{tabular}

recovering the sensor's initial conductance. Sayago et al. reported two different methods for the functionalization of SWCNTs with $\mathrm{Pd}$ for $\mathrm{H}_{2}$ sensors [50]. The SWCNTs either being chemically functionalized with Pd or sputtered with Pd showed increased resistance when exposed to 0.1$2 \% \mathrm{H}_{2}$ at room temperature. The chemically functionalized Pd-SWCNTs sensors were superior to the sputtered ones. Both response time and response decreased with increasing temperature. However, only aged sensors provided good selectivity with minimum response to octane, toluene and ammonia in reversible and reproducible experiments performed at room temperature. This might be related to changes in the employed material, for example, introduction of carboxylic acid functionalities due to oxygen exposure, and/or to the complete removal of solvent residues, that might increase either the effective surface area or the hydrogen adsorption capabilities. Mubeen et al. developed a simple electrochemical functionalization method to fabricate aa $\mathrm{H}_{2}$ nanosensor by site-specific electrodeposition of $\mathrm{Pd}$ nanoparticles on SWCNTs [51]. Optimal sensing performance was obtained by varying the synthesis conditions (e.g., Pd electrodeposition charge, deposition potential and initial baseline resistance of the SWCNTs network). At room temperature, the optimized sensor showed good response toward $\mathrm{H}_{2}(0.42 \%$ resistance change per $\mathrm{ppm})$ with a detection limit of $100 \mathrm{ppm}$ and a linear response up to $1000 \mathrm{ppm}$. The response time decreased from tens of minutes to a few minutes with increasing hydrogen concentration. The sensor's recovery time was shortened under humid air compared to dry air condition. Complete recovery was observed for the sensors at all tested concentration range and recovery time varied from 20 minutes at $100 \mathrm{ppm}$ to
55 minutes at 1000 ppm. $\mathrm{H}_{2}$ sensors based on SWCNTs decorated with Pd nanoparticles via a simple electrodeposition process on a flexible plastic substrate have also been demonstrated [52]. The Pd functionalized SWCNTs flexible sensors could readily detect $100 \mathrm{ppm}_{2}$ (with 5\% relative response) at room temperature. The response time for $37 \%$ of the steady state resistance change was in the range of a few seconds up to 1 minute, or close to 5 minutes to reach a value close to steady state. The typical flexible sensors exhibited response of $\sim 75 \%$ for $0.05 \%$ hydrogen in air and response time of $\sim 3$ seconds for $1 \%$ hydrogen at room temperature. The mechanical bendability of the flexible sensors was proved to have negligible effect $(<5 \%)$ on the sensing performance. Oakley et al. prepared SWCNTs films by a simple filtration process, subsequently coated with palladium [53]. The Pd-coated SWCNTs film could detect $10 \mathrm{ppm}_{2}$ at room temperature and relative

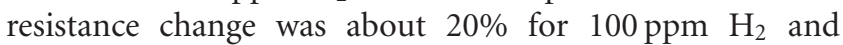
$40 \%$ for $500 \mathrm{ppm} \mathrm{H}_{2}$. The time for substantial recovery is less than 30 seconds when exposed to air and the power consumption is $0.25 \mathrm{~mW}$. Ding et al. [54] fabricated robust CNTs-based hydrogen sensors with aligned CNTs grown in an anodic aluminum oxide (AAO) template. Without Pd modification, an Au-electrode CNTs sensor showed no response to $\mathrm{H}_{2}$. A Pd-electrode CNTs sensor could detect $\mathrm{H}_{2}$ (from $0.1 \%$ to $1.5 \% \mathrm{H}_{2}$ ) with a reversible response at room temperature. Typical response time of the Pd-electrode CNTs sensor is about 3-4 minutes. Furthermore, the CNTs grown in the AAO template were also demonstrated to be a good supporting material for nanoporous Pd film sensors. Typical response time of the CNTs-supported Pd film sensor is less than 7 minutes for dilute $\mathrm{H}_{2}$, and less 
than 4 minutes for medium concentration of $\mathrm{H}_{2}$. For the Pdelectrode CNT sensor, CNTs provide better contacts between the Pd-electrode and the substrate, while for the CNTsupported Pd film sensor, CNTs provide a better mechanical support and anchoring role so that the Pd film does not peel off easily after exposure to $\mathrm{H}_{2}$. The $\mathrm{Pd}$ film in the CNT-supported Pd film sensor mainly contributes to the total resistance of the sensor. Whereas, in the Pd-electrode CNT sensor, both the Pd film and the CNTs contribute to the total resistance of the sensor. Since the CNTs are less sensitive to hydrogen gas than the $\mathrm{Pd}$ is, less response has been found with the Pd-electrode CNT sensor than that with the CNT-supported Pd film sensor. SWCNTs coated with Pd nanoparticles by sputtering have been used to detect $\mathrm{CH}_{4}$ ranging from 6 to $100 \mathrm{ppm}$. At room temperature, the Pd coated SWCNTs sensors give reproducible trends and consistently respond to heat and UV light for speed recovery [55]. A charge transfer sensing mechanism was proposed. Hydrogen atoms in $\mathrm{CH}_{4}$ attract electrons from $\mathrm{Pd}$, and electrons are withdrawn from the SWCNTs. This results in a weakly bound complex $\mathrm{Pd}^{\delta+}\left(\mathrm{CH}_{4}\right)^{\delta-}$, leaving more holes in the SWCNTs, thereby increasing the conductance of p-type or hole-occupied SWCNTs when exposed to $\mathrm{CH}_{4}$. $\mathrm{Li}$ et al. reported a composite of MWCNTs/Pd prepared by a facile method of chemical reduction exhibited a reversible and reproducible response magnitude of $4.5 \%$ toward $2 \% \mathrm{CH}_{4}$ at room temperature [56]. The response and recovery time was estimated to be 310 seconds and 176 seconds, respectively. The inert $\mathrm{CH}_{4}$ does not undergo a charge transfer reaction with the MWCNTs to initiate a change in electrical properties, so MWCNTs alone are insensitive to methane. In the composite, the palladium nanoparticles undergo a weak interaction with the $\mathrm{CH}_{4}$ molecules adsorbed on the composite to form a long range weakly bound complex $\mathrm{Pd}^{\delta+}\left(\mathrm{CH}_{4}\right)^{\delta-}$ at room temperature. The MWCNTs donate electrons to $\mathrm{Pd}^{0}$ to promote the formation of the complex where $\mathrm{CH}_{4}$ is electronegative. The hole density in the MWCNTs is thus increased, resulting in a higher current in the composite.

Carbon nanotubes have also been modified with other metals for gas sensors. Kumar et al. fabricated $\mathrm{H}_{2}$ sensors based on MWCNTs functionalized with $\mathrm{Pt}$ or $\mathrm{Pd}$ by aqueous solution reduction of $\mathrm{H}_{2} \mathrm{PtCl}_{6}$ or $\mathrm{PdCl}_{2}$ [57, 58]. They showed high response and reversibility at room temperature. The response time and recovery time are 10 minutes and 15 minutes for MWCNTs functionalized with $\mathrm{Pt}$, respectively. Both the response time and recovery time are about 7 minutes for Pd-MWCNTs. The dissolved atomic hydrogen in $\mathrm{Pt}$ or Pd interstitials and the chemisorbed hydrogen on MWNTs combine with oxygen in air, departing the Pt-MWCNTs or Pd-MWCNTs system in the form of water and thus recovering the sample electrical characteristics. Hydrogen sensing properties of Pd-decorated SWCNTs bundles and Pd-decorated exfoliated SWCNTs via Arabic gum treatment showed an improved hydrogen sensing behavior due to improved accessible surface area [59]. The response time and recovery time are 10 minutes and 14 minutes for Pdexfoliated SWCNTs, respectively. The exfoliated SWCNTs are loosely bound and this results in an increase in accessible surface area of SWCNTs which in turn decreases the time scale for the adsorbed hydrogen to escape from the sample surface. The resistance change in Pd-exfoliated SWCNTs is about $15 \%$, which is more than doubled when compared with nonexfoliated Pd-SWNT (about 5\%). Kamarchuk et al. demonstrated the effect of point heterocontact between SWCNTs and a gold microwire on the gas response [60]. AuSWCNTs heterocontact sensors exhibit high response to $\mathrm{NH}_{3}$ and $\mathrm{NO}_{2}$ with fast response and relaxation and these two gases can be distinguished based on the direction of charge transfer between the analyte and the SWCNTs. The response

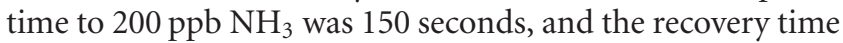
was 200 seconds. The mechanism of sensing is associated with formation of a thin conductive channel between Au and SWCNTs but the sign of the resistance change is controlled by the SWCNTs. Penza et al. demonstrated $\mathrm{Au}$ and $\mathrm{Pt}$ nanocluster functionalized MWCNTs chemiresistive sensors for $\mathrm{NO}_{2}$ and $\mathrm{NH}_{3}$ sensing at working temperature of 100$250^{\circ} \mathrm{C}$ [61]. Au and Pt nanoclusters were sputtered on the surface of MWCNTs. The gas response of Pt- and Aufunctionalized MWCNT gas sensors significantly improved by a factor up to an order of magnitude for $\mathrm{NH}_{3}$ and $\mathrm{NO}_{2}$ detection, respectively. The enhancement of the gas response of the metal-modified MWCNT sensors could be caused by a combination of two additional effects of (1) direct charge injection and (2) catalytically induced charge into functionalized MWCNTs. Espinosa et al. coated MWCNTs with $\mathrm{Au}$ or $\mathrm{Ag}$ nanoclusters deposited by electron beam evaporation [62]. The decorated MWCNTs' sensors were able to detect $\mathrm{NO}_{2}$ at the range of $500 \mathrm{ppb}-6.5 \mathrm{ppm}$ at room temperature and significantly more selective than sensors based on MWCNTs without metal nanoclusters attached to their surface. The response of Au-MWCNTs sensors to $\mathrm{NO}_{2}$ was higher than the one of Ag-MWCNTs. Both materials showed a reversible behavior after $\mathrm{NO}_{2}$ exposure, provided that their operating temperature was raised to $150^{\circ} \mathrm{C}$ in a flow of dry air. Upon adsorption of $\mathrm{NO}_{2}$ gas molecules, there is a significant charge transfer between the metallic nanoclusters and the nanotubes, which results in a measurable change in the overall conductance of the active film. The decorated MWCNTs sensors were almost insensitive to CO, ethanol, or ethylene at concentrations up to $50 \mathrm{ppm}$.

Metal nanoparticle functionalized CNTs sensor arrays have also been reported. Star et al. fabricated gas sensor arrays by site-selective electroplating of $\mathrm{Au}, \mathrm{Pt}, \mathrm{Pd}$, and $\mathrm{Rh}$ metals on isolated SWCNTs networks located on a single chip [63]. The difference in catalytic activities of the metal nanoparticles caused different selectivities for the detection of $\mathrm{H}_{2}, \mathrm{CH}_{4}, \mathrm{CO}, \mathrm{H}_{2} \mathrm{~S}, \mathrm{NH}_{3}$, and $\mathrm{NO}_{2}$. The output of the sensor array was analyzed using principal component analysis (PCA) and partial least squares regression (PLS) in order to identify the above-mentioned gases. Lu et al. demonstrated a gas sensor array composed of 32 sensing elements with pristine, metal-decorated ( $\mathrm{Pd}, \mathrm{Au})$, and polymer-decorated SWCNTs for discriminating gases such as $\mathrm{NO}_{2}, \mathrm{HCN}, \mathrm{HCl}$, $\mathrm{Cl}_{2}$, acetone, and benzene at ppm levels [64]. CNTs-based technology holds the potential to excel in the design of arrays because the inherently small size of CNTs devices will allow for the integration of large numbers of functionalized 
CNTs sensor elements that would show a unique response to numerous species.

Gas-sensing performance of metal functionalized CNT gas sensors is summarized in Table 3 .

\subsection{Gas Sensors Based on Nanostructured Oxides Modified} CNTs. Metal oxide gas sensors have been investigated extensively since decades ago owing to their advantages of high response to pollutant gases, fast response and recovery, low cost, easy implementation, and small in size. However, they are usually operated at temperature range between 200 and $800^{\circ} \mathrm{C}$. Sensors based on metal oxides $\left(\mathrm{SnO}_{2}, \mathrm{WO}_{3}\right.$ or $\left.\mathrm{TiO}_{2}\right)$ modified CNTs can detect gases such as $\mathrm{NO}_{2}, \mathrm{CO}, \mathrm{NH}_{3}$ and ethanol vapors at low operating temperature with improved sensing properties.

Recently, sensors based on SWCNTs/ $\mathrm{SnO}_{2}$ nanocomposites with enhanced gas sensing performance have been reported. Wei et al. constructed $\mathrm{SWCNTs} / \mathrm{SnO}_{2}$ gas sensor by incorporating SWCNTs into a $\mathrm{SnO}_{2}$ substrate. The fabrication involved heat treatment of the SWCNTs/SnO layer, which was fabricated by spin coating using an organometallic solution dispersed with SWCNTs [65]. The prepared $\mathrm{SWCNTs} / \mathrm{SnO}_{2}$ nanocomposite sensors exhibit much higher response and recovery property in detecting $\mathrm{NO}_{2}$ at room temperature than the blank $\mathrm{SnO}_{2}$ sensor. The response time and recovery time are 9 minutes and 1.5 minute, respectively. A model is presented to relate potential barriers to electronic conduction in the hybrid material. This model suggests that the high response is associated with the stretching of the depletion layers at the grain boundaries of $\mathrm{SnO}_{2}$ and the SWCNTs interfaces when detected gases are adsorbed. Gong et al. developed MEMS-based sensors integrated with nanocrystalline SWCNTs $/ \mathrm{SnO}_{2}$ sensing films realized by a polymeric sol-gel process [66]. The response of the SWCNTs $/ \mathrm{SnO}_{2}$ sensor is three times greater than that of the pure $\mathrm{SnO}_{2}$ sensor with faster response and recovery in hydrogen detection. The response time and recovery time are $2-5$ seconds and $3-5$ seconds at the working temperature of 200 and $250^{\circ} \mathrm{C}$, respectively. The working temperature has been reduced as low as $150^{\circ} \mathrm{C}$. The greatly improved performance is attributed to the effective gas accessing nanopasses formed by SWCNTs. Hoa et al. fabricate an $\mathrm{NH}_{3}$ sensor with a composite of SWCNTs and $\mathrm{SnO}_{2}$ [67]. The sensor could detect the concentration of $\mathrm{NH}_{3}$ down to $10 \mathrm{ppm}$ at room temperature, and exhibited a fast response time of 100 seconds and recovery time of about 3.2 minutes. The SWCNTs in the matrix of $\mathrm{SnO}_{2}$ provide the main conducting channels that effectively varies in its conductance upon adsorption of $\mathrm{NH}_{3}$. The recovery time depends on the bonding force of $\mathrm{NH}_{3}$ molecules to the SWCNT surface with respect to the desorption under nitrogen flowing. Thus, it can vary with the nitrogen flow rate.

MWCNTs have also been incorporated with $\mathrm{SnO}_{2}$ for gas sensors with improved sensing properties. Liu et al. synthesized a compound material of MWCNTs coated with $\mathrm{SnO}_{2}$ at ambient conditions [68]. The MWCNTs/ $/ \mathrm{SnO}_{2}$ sensor exhibited good sensing responses to liquefied petroleum gas (LPG) and ethanol $\left(\mathrm{C}_{2} \mathrm{H}_{5} \mathrm{OH}\right)$ vapor with fast response and recovery within seconds at temperature of $335^{\circ} \mathrm{C}$. Furthermore, the gas sensor response increased linearly with the increment of gas concentration of LPG and ethanol. The high response and low resistance may be attributed to the particular electrical transport mechanism. The resistance of the sensor is dominated by the barriers among the $\mathrm{SnO}_{2}$ grains on the MWCNTs. Electrons travel through the $\mathrm{SnO}_{2}$ grains into the MWCNTs, and then conduct in the MWCNTs with low resistance. Chen et al. synthesized MWCNTs $/ \mathrm{SnO}_{2}$ core/shell nanostructures by a simple wet-chemical method [69]. The thickness of the $\mathrm{SnO}_{2}$ shell was about $10 \mathrm{~nm}$ and the diameters of the $\mathrm{SnO}_{2}$ particles were 2-8nm. Sensors based on the core/shell heterostructures exhibited enhanced ethanol sensing properties at working temperature of $300^{\circ} \mathrm{C}$. The response to $50 \mathrm{ppm}$ ethanol was up to 24.5 , and the response time and recovery time were about 1 and 10 seconds, respectively. In addition, the fluctuation of the response was less than $\pm 3 \%$ on remeasurement after 3 months. The enhanced ethanol sensing properties are attributed to the small size of the $\mathrm{SnO}_{2}$ nanoparticles and the heterojunction of the core/shell structures of $\mathrm{MWCNTs} / \mathrm{SnO}_{2}$. Espinosa et al. demonstrated that the addition of a small quantity of oxygen-functionalized MWCNTs to metal oxides $\left(\mathrm{SnO}_{2}\right.$, $\mathrm{WO}_{3}$ or $\mathrm{TiO}_{2}$ ) can significantly improve the detection capability of metal oxides-based sensors at low operating temperature [70]. In particular, microsensors based on $\mathrm{SnO}_{2} / \mathrm{MWCNTs}$ hybrid films operated at room temperature showed higher response towards $\mathrm{NO}_{2}$ in the ppb range. $\mathrm{TiO}_{2} /$ MWCNTs sensors showed the lowest response to $\mathrm{NO}_{2}$ and irresponsive to $\mathrm{CO}$ even at $150^{\circ} \mathrm{C}$. The recovery time of the $\mathrm{SnO}_{2} / \mathrm{MWCNT}$ sensors was reduced from 45 minutes at room temperature down to 20 minutes at $150^{\circ} \mathrm{C}$, while in the case of $\mathrm{WO}_{3} / \mathrm{MWCNT}$ sensors, the recovery time was reduced from 120 to 45 minutes. Furthermore, the response is fully reversible. A mechanism of response based on the development of two depletion layers, one at the surface of metal oxide grains and another at the interface of the n-metal oxide/p-MWCNT heterostructure, is postulated to be responsible for the improvement observed. Hieu et al. fabricated an $\mathrm{SnO}_{2}$ /MWCNTs composite-based $\mathrm{NH}_{3}$ sensor by thin film microelectronic technique [71]. At room temperature, the optimal composite sensor exhibited much higher response and faster response recovery (less than 5 minutes) to $\mathrm{NH}_{3}$ with concentration from 60 to $800 \mathrm{ppm}$, in comparison with the CNTs-based $\mathrm{NH}_{3}$ sensor. The enhancement of the response to $\mathrm{NH}_{3}$ of the composite sensors may result from the $\mathrm{p}$ - $\mathrm{n}$ heterojunction formed by $\mathrm{CNTs}$ and $\mathrm{SnO}_{2}$ nanoparticles. The response of the MWCNTs $/ \mathrm{SnO}_{2}$ composite thin film gas sensor strongly depends on the preparation process of the sensitive film. The composite thin film with $15 \mathrm{wt} \%$ MWCNTs with diameter of $60-100 \mathrm{~nm}$, the calcination temperature of $530^{\circ} \mathrm{C}$ under vacuum of $10^{-2}$ Torr, and the film thickness of $400 \mathrm{~nm}$ are optimal conditions. The response of the sensor to $\mathrm{NH}_{3}$ increases with increasing MWCNTs content and the composites using MWCNTs with the larger diameter show higher response because larger diameter MWCNTs would increase the number of gas molecules adsorbed on the 
TABLE 3: Summary of sensing performance of metal functionalized CNT sensors. (Note: N/S = Not-stated.)

\begin{tabular}{|c|c|c|c|c|c|c|c|}
\hline Metal & CNT type & Sensor configuration & Targeted analytes & Detection limit & Response time & Recovery time & Reference \\
\hline $\mathrm{Pd}$ & S-SWCNT & FET & $\mathrm{H}_{2}$ & $<40 \mathrm{ppm}$ & $\begin{array}{l}5-10 \mathrm{~s} \text { (for half } \\
\text { resistance change) }\end{array}$ & $400 \mathrm{~s}$ & [49] \\
\hline $\mathrm{Pd}$ & SWCNTs & Resistor & $\mathrm{H}_{2}$ & $1000 \mathrm{ppm}$ & $\mathrm{N} / \mathrm{S}$ & $\mathrm{N} / \mathrm{S}$ & {$[50]$} \\
\hline $\mathrm{Pd}$ & SWCNTs & Resistor & $\mathrm{H}_{2}$ & $100 \mathrm{ppm}$ & $10 \mathrm{~min}$ & $20 \mathrm{~min}$ & {$[51]$} \\
\hline $\mathrm{Pd}$ & SWCNTs & Resistor & $\mathrm{H}_{2}$ & $100 \mathrm{ppm}$ & $\begin{array}{l}3-60 \mathrm{~s} \text { (for } 36.8 \% \\
\text { resistance change) }\end{array}$ & $\sim 5 \min$ & {$[52]$} \\
\hline $\mathrm{Pd}$ & SWCNTs & Resistor & $\mathrm{H}_{2}$ & $\sim 10 \mathrm{ppm}$ & $<10 \mathrm{~min}$ & $<30 s$ & {$[53]$} \\
\hline $\mathrm{Pd}$ & ACNTs & Resistor & $\mathrm{H}_{2}$ & $100 \mathrm{ppm}$ & $<7$ min & $\mathrm{N} / \mathrm{S}$ & {$[54]$} \\
\hline $\mathrm{Pd}$ & SWCNTs & Resistor & $\mathrm{CH}_{4}$ & $6 \mathrm{ppm}$ & $2-4 \mathrm{~min}$ & $\mathrm{~N} / \mathrm{S}$ & {$[55]$} \\
\hline $\mathrm{Pd}$ & MWCNTs & Resistor & $\mathrm{CH}_{4}$ & $2 \%$ & $\sim 310 \mathrm{~s}$ & $\sim 176 \mathrm{~s}$ & {$[56]$} \\
\hline $\mathrm{Pt}$ & MWCNTs & Resistor & $\mathrm{H}_{2}$ & $\mathrm{~N} / \mathrm{S}$ & $10 \mathrm{~min}$ & $15 \mathrm{~min}$ & {$[57]$} \\
\hline $\mathrm{Pd}$ & MWCNTs & Resistor & $\mathrm{H}_{2}$ & $\mathrm{~N} / \mathrm{S}$ & $7 \mathrm{~min}$ & $7 \mathrm{~min}$ & {$[58]$} \\
\hline $\mathrm{Pt}$ & MWCNTs & Resistor & $\mathrm{H}_{2}, \mathrm{NO}_{2}, \mathrm{H}_{2} \mathrm{O}$ & $\mathrm{N} / \mathrm{S}$ & $\sim 10 \mathrm{~min}$ & $\sim 14 \mathrm{~min}$ & {$[59]$} \\
\hline $\mathrm{Au}$ & SWCNTs & Resistor & $\mathrm{NH}_{3}, \mathrm{NO}_{2}$ & $<120 \mathrm{ppb} \mathrm{NH}$ & $150 \mathrm{~s}$ & $200 \mathrm{~s}$ & {$[60]$} \\
\hline $\mathrm{Au}, \mathrm{Pt}$ & MWCNTs & Resistor & $\mathrm{NO}_{2}, \mathrm{NH}_{3}$ & $\begin{array}{l}100 \mathrm{ppb} \mathrm{NO} \text {, } \\
5 \mathrm{ppm} \mathrm{NH} 3\end{array}$ & $\mathrm{~N} / \mathrm{S}$ & $\mathrm{N} / \mathrm{S}$ & {$[61]$} \\
\hline $\mathrm{Au}, \mathrm{Ag}$ & MWCNTs & Resistor & $\mathrm{NO}_{2}$ & $500 \mathrm{ppb} \mathrm{\textrm {NO } _ { 2 }}$ & $\sim 20 \mathrm{~min}$ & $\mathrm{~N} / \mathrm{S}$ & {$[62]$} \\
\hline Pt, Pd, Sn, Rh & SWCNTs & FET & $\mathrm{H}_{2}, \mathrm{CH}_{4}, \mathrm{CO}, \mathrm{H}_{2} \mathrm{~S}$ & $\mathrm{~N} / \mathrm{S}$ & $\sim 5 \min$ & $\mathrm{N} / \mathrm{S}$ & {$[63]$} \\
\hline $\mathrm{Pd}, \mathrm{Au}$ & SWCNTs & Resistor & $\begin{array}{l}\mathrm{NO}_{2}, \mathrm{HCN}, \mathrm{HCl} \text {, } \\
\mathrm{Cl}_{2} \text {, acetone, } \\
\text { benzene }\end{array}$ & $5 \mathrm{ppm}$ & $\mathrm{N} / \mathrm{S}$ & $\mathrm{N} / \mathrm{S}$ & {$[64]$} \\
\hline
\end{tabular}

material. Increasing the annealing temperature may result in the improvement of the contact between $\mathrm{SnO}_{2}$ nanoparticles and CNTs but the higher calcinated temperature may also result in burning of CNTs by residual oxygen or damaging of CNTs structure. An increase in thickness of the thin film composite sensors results in a decrease in the response due to the increase of the diffusion length of gases. Wang et al. reported a gas sensor based on $\mathrm{SnO}_{2}$ doped with hydroxyl functionalized MWCNTs for detecting indoor formaldehyde [72]. The response of the MWCNTs-doped $\mathrm{SnO}_{2}$ sensor was much higher than that of an undoped $\mathrm{SnO}_{2}$ sensor. The lowest concentration of formaldehyde vapor detected by a 5 wt.\% MWCNTs-doped $\mathrm{SnO}_{2}$ sensor was $0.03 \mathrm{ppm}$. The response and recovery time of the sensor to $0.05 \mathrm{ppm}$ formaldehyde vapor is about 100 seconds and 90 seconds at $250^{\circ} \mathrm{C}$. The sensor response to formaldehyde is higher than to acetone, methanol, toluene, benzene and ammonia. High adsorption capacity of MWCNTs enhance the adsorption ability of the $\mathrm{SnO}_{2}$ for formaldehyde molecules. Reducing molecules like formaldehyde act as temporary ntype dopants when they interact with CNTs, which leads to a decrease in resistance and hence to an increase in response of the MWCNTs doped $\mathrm{SnO}_{2}$ sensor. The MWCNTs-doped $\mathrm{SnO}_{2}$ material contains at least three kinds of interfaces, such as between $\mathrm{SnO}_{2}$ grains, between MWCNTs, and between $\mathrm{SnO}_{2}$ grains and CNTs (existence of a heterostructure). Bittencourt et al. demonstrated that $\mathrm{WO}_{3}$ films impregnated with MWCNTs showed response to $500 \mathrm{ppb} \mathrm{NO}_{2}$ under ambient conditions and $10 \mathrm{ppm} \mathrm{NH}_{3}$ at $150^{\circ} \mathrm{C}$, far below the typical operating temperature of $\mathrm{WO}_{3}$ sensors [73]. Oxygen plasma functionalized MWCNTs were added to $\mathrm{WO}_{3}$ by drop-coating deposition method. The adsorption at the surface of CNTs modifies the depletion layer at the n- $\mathrm{WO}_{3} / \mathrm{p}$ MWCNTs heterojunctions and this results in the modulation of the depletion layer at the surface of $\mathrm{WO}_{3}$ grains. This change in the depletion layer at the $\mathrm{n} / \mathrm{p}$ junction that induces change in the $\mathrm{WO}_{3}$ matrix may explain the improvement in response shown by hybrid sensors.

The detection of acetone and $\mathrm{NH}_{3}$ was found to be possible at ambient temperature with $\mathrm{TiO}_{2} / \mathrm{MWCNTs}$ gas sensors fabricated by sol-gel method [74]. The $\mathrm{TiO}_{2} / \mathrm{MWCNTs}$ composites obtained by $\mathrm{Ti}$-isopropoxide route are reported as room temperature sensitive coatings. Sensing was highly reproducible in the composites, with fast adsorption/desorption cycles at room temperature. Composites based on as-received MWCNTs show an increase in films resistance during acetone and ammonia adsorption, while composites based on functionalized MWCNTs show longer acetone desorption time (300 seconds) and a decrease in resistance during ammonia sensing. Theoretical ab initio calculations predicted an inversion in the acetone $\rightarrow$ $\mathrm{Ti}_{x} \mathrm{O}_{y} / \mathrm{CNT}$ charge transfer direction as the size of the oxide cluster increases, explaining the inverse changes in resistance of the composites versus the components but have not been successful in explaining the differences observed in the composites during $\mathrm{NH}_{3}$ adsorption. Detection of $\mathrm{NH}_{3}$ might be also possible through the intertube modulation effect (i.e., MWCNT- $\mathrm{TiO}_{2} / \mathrm{NH}_{3}-\mathrm{MWCNT}$ junctions) and where titania is acting as a buffer layer to avoid MWCNTs dedoping. Llobet et al. fabricated resistive oxygen sensors based on $\mathrm{TiO}_{2} / \mathrm{MWCNTs}$ hybrids by drop-coating method [75]. The hybrid layers based on $\mathrm{TiO}_{2}$ and MWCNTs possess 
TABLE 4: Summary of sensing performance of metal oxide functionalized CNT sensors. (Note: N/S = Not-stated.)

\begin{tabular}{|c|c|c|c|c|c|c|c|}
\hline Metal oxide & CNT type & $\begin{array}{l}\text { Sensor } \\
\text { configuration }\end{array}$ & Targeted analytes & $\begin{array}{l}\text { Detection } \\
\text { limit }\end{array}$ & Response time & Recovery time & Reference \\
\hline $\mathrm{SnO}_{2}$ & SWCNTs & Resistor & $\mathrm{NO}_{2}$ & $\mathrm{~N} / \mathrm{S}$ & $9 \min$ & $1.5 \mathrm{~min}$ & {$[65]$} \\
\hline $\mathrm{SnO}_{2}$ & SWCNTs & Resistor & $\mathrm{H}_{2}$ & $300 \mathrm{ppm}$ & $2-5 \mathrm{~s}\left(200-250^{\circ} \mathrm{C}\right)$ & $3-5 \mathrm{~s}\left(200-250^{\circ} \mathrm{C}\right)$ & {$[66]$} \\
\hline $\mathrm{SnO}_{2}$ & SWCNTs & Resistor & $\mathrm{NH}_{3}$ & $10 \mathrm{ppm}$ & $\sim 100 \mathrm{~s}$ & $\sim 3.2 \mathrm{~min}$ & {$[67]$} \\
\hline $\mathrm{SnO}_{2}$ & MWCNTs & Resistor & $\mathrm{LPG}, \mathrm{C}_{2} \mathrm{H}_{5} \mathrm{OH}$ & $10 \mathrm{ppm}$ & $\mathrm{N} / \mathrm{S}$ & $\mathrm{N} / \mathrm{S}$ & {$[68]$} \\
\hline $\mathrm{SnO}_{2}$ & MWCNTs & Resistor & $\mathrm{C}_{2} \mathrm{H}_{5} \mathrm{OH}$ & $10 \mathrm{ppm}$ & $\sim 1 \mathrm{~s}\left(300^{\circ} \mathrm{C}\right)$ & $\sim 10 \mathrm{~s}\left(300^{\circ} \mathrm{C}\right)$ & [69] \\
\hline $\mathrm{SnO}_{2}$ & MWCNTs & Resistor & $\mathrm{NO}_{2}$ & $100 \mathrm{ppb}$ & $\mathrm{N} / \mathrm{S}$ & $20 \min \left(150^{\circ} \mathrm{C}\right)$ & [70] \\
\hline $\mathrm{SnO}_{2}$ & MWCNTs & Resistor & $\mathrm{NH}_{3}$ & $60 \mathrm{ppm}$ & $<5 \mathrm{~min}$ & $<5 \min$ & {$[71]$} \\
\hline $\mathrm{SnO}_{2}$ & MWCNTs & Resistor & formaldehyde & $0.03 \mathrm{ppm}$ & $100 \mathrm{~s}\left(250^{\circ} \mathrm{C}\right)$ & $90 \mathrm{~s}\left(250^{\circ} \mathrm{C}\right)$ & {$[72]$} \\
\hline $\mathrm{WO}_{3}$ & MWCNTs & Resistor & $\mathrm{NO}_{2}, \mathrm{CO}, \mathrm{NH}_{3}$ & $\begin{array}{l}500 \mathrm{ppb} \\
\mathrm{NO}_{2}, \\
10 \mathrm{ppm} \mathrm{CO}, \\
10 \mathrm{ppm} \\
\mathrm{NH}_{3}\end{array}$ & $\mathrm{~N} / \mathrm{S}$ & $\mathrm{N} / \mathrm{S}$ & {$[73]$} \\
\hline $\mathrm{TiO}_{2}$ & MWCNTs & Resistor & acetone, $\mathrm{NH}_{3}$ & $\mathrm{~N} / \mathrm{S}$ & $10-40 \mathrm{~s}$ (acetone) & $10-300$ s (acetone) & {$[74]$} \\
\hline $\mathrm{TiO}_{2}$ & CNTs & Resistor & $\mathrm{O}_{2}$ & $10 \mathrm{ppm}$ & $5-8 \min \left(350-550^{\circ} \mathrm{C}\right)$ & $\sim 20 \min \left(350^{\circ} \mathrm{C}\right)$ & {$[75]$} \\
\hline $\mathrm{SnO}_{2}, \mathrm{TiO}_{2}$ & $\begin{array}{l}\text { SWCNTs, } \\
\text { MWCNTs }\end{array}$ & Resistor & $\mathrm{C}_{2} \mathrm{H}_{5} \mathrm{OH}$ & $100 \mathrm{ppm}$ & $<10 \mathrm{~s}\left(210-400^{\circ} \mathrm{C}\right)$ & $<10 \mathrm{~s}\left(210-400^{\circ} \mathrm{C}\right)$ & {$[76]$} \\
\hline
\end{tabular}

an unprecedented responsiveness toward oxygen (i.e., more than four times higher than that shown by optimized Nb-doped $\mathrm{TiO}_{2}$ films). Furthermore, hybrid sensors containing MWCNTs respond at significantly lower operating temperature than their nonhybrid counterparts. These new hybrid sensors show a strong potential for monitoring traces of oxygen (i.e., $<10 \mathrm{ppm}$ ) in a flow of $\mathrm{CO}_{2}$. The heterostructure $\mathrm{n}-\mathrm{TiO}_{2} / \mathrm{p}$-MWCNTs can be formed at the interface between titania and carbon nanotubes. Hybrid sensors are significantly more responsive to oxygen than pure or $\mathrm{Nb}$-doped titania sensors because a slight change in the concentration of adsorbed oxygen at its surface can result in a significant change in the depletion layer at the $\mathrm{n}-\mathrm{TiO}_{2} / \mathrm{p}-\mathrm{MWCNT}$ heterostructure. Duy et al. constructed $\mathrm{SnO}_{2}-\mathrm{TiO}_{2}$ and MWCNTs-included $\mathrm{SnO}_{2}-\mathrm{TiO}_{2}$ thin films by sol-gel spin coating [76]. The inclusion of MWCNTs at specific contents into the mixed oxides improved response of the sensor at low operating temperature (below $280^{\circ} \mathrm{C}$ ). The response and recovery time of the sensors is less than 10 seconds at operating temperature of $210-400^{\circ} \mathrm{C}$. The improvement of the gas sensor performance and the shift of operation temperature toward the lower temperature region can be attributed to the amplification effect of the $\mathrm{p}-\mathrm{n}$ junctions in addition to the effect of the grain boundaries.

Gas-sensing performance of metal oxides functionalized CNT gas sensors is summarized in Table 4 .

\section{Gas Sensors Based on Heteroatom-Containing Nanotubes}

Doping of SWCNTs with heteroatoms will change the electronic properties of the nanotubes, thus changing their interaction with gas molecules and their sensing properties as well. Theoretical calculation predicted that SWCNTs doping with $\mathrm{B}, \mathrm{N}$, and so forth will enhance their sensing properties toward electron-rich or electron-scarce molecules. Pristine CNTs-based gas sensors are currently limited to sense gases such as $\mathrm{NH}_{3}, \mathrm{NO}_{2}, \mathrm{SO}_{2}, \mathrm{O}_{2}$, and $\mathrm{NO}$. However, many highly toxic gases (such as $\mathrm{CO}$ and formaldehyde) cannot be detected using the pristine CNTs gas sensors. To improve gas-sensing performance, Peng et al. propose to use B or N doped SWCNTs, or composite BxCyNz nanotubes as sensing element [77]. Using first-principle calculations, they demonstrated that these sensors can detect $\mathrm{CO}$ and water molecules, and more important, the response of these sensors can be controlled by adjusting the doping level of heteroatoms in a nanotube. Subsequently, Wang et al. investigated reactivities of the intrinsic and Al-doped SWCNTs with CO by density functional theory (DFT) calculations [78]. The Al-doped SWCNTs present high response to CO, compared with the intrinsic SWCNTs. Wang et al. [79] and Zhang et al. [80] investigated reactivities of B-doped SWCNTs with $\mathrm{HCOH}$ or HCN by using density functional theory calculations. Compared with the intrinsic SWCNTs, B-doped SWCNTs presents high response to $\mathrm{HCOH}$ or $\mathrm{HCN}$. This is attributed to the strong chemical interaction between the electronrich oxygen atom in $\mathrm{HCOH}$ or nitrogen atom in $\mathrm{HCN}$ and the electron-scarce boron atom of the doped SWCNTs. Bai and Zhou [81] investigated the adsorption of $\mathrm{NH}_{3}$ and $\mathrm{NO}_{2}$ in $\mathrm{B}$ - or $\mathrm{N}$-doped SWCNTs by using density functional computations. The $\mathrm{N}$-doping did not change $\mathrm{NH}_{3}$ adsorption on SWCNTs but B-doped SWCNTs could be used for $\mathrm{NH}_{3}$ sensing. Both $\mathrm{B}$ - and $\mathrm{N}$-doping made $\mathrm{NO}_{2}$ chemisorption feasible in SWCNTs but the binding of $\mathrm{NO}_{2}$ with $\mathrm{B}$ was too strong, indicating an impractical recovery time as gas sensors. 


\section{Conclusion and Remark}

Carbon nanotubes are active elements for sensing a broad variety of gases with high response because of their unique structure and electronic properties, and their rich configurations as well. Modification of carbon nanotubes with functional groups and metal nanoparticles or incorporation of carbon nanotubes with polymers and metal oxides will greatly enhance the selectivity of the carbon nanotubes-based sensors. CNTs-based gas sensors have proved to work well at room temperature, which reduces power consumption of the device and enables the safer detection of flammable gases. However, much effort has to be done before the practical application of CNTs-based gas sensors. Firstly, CNTs with defined structure and property need to be produced in large quantity at low cost. Secondly, the sensing properties, especially the selectivity and recovery, have to be improved. For practical application, gas sensors are required to be with high selectivity, low operating temperature, quick response and recovery. One common disadvantage of CNTsbased gas sensors is the potential interference from relative humidity at room temperature. Other main drawbacks are slow recovery and poor selectivity. There have been a variety of attempts such as heat treatment, ultraviolet light irradiation, increasing carrier gas flux, and modification of CNTs with functional groups or other additives to overcome the limitation. The instability of the CNTs in air at elevated temperature will limit CNTs-based gas sensors being operated at high temperature. CNTs-based gas sensors are sensitive to many gases or vapors such as $\mathrm{NO}_{2}, \mathrm{NH}_{3}$, $\mathrm{H}_{2}, \mathrm{CH}_{4}$, and $\mathrm{Cl}_{2}$ at room temperature but the operating temperature of CNTs-based gas sensors for detecting $\mathrm{O}_{2}$, $\mathrm{C}_{2} \mathrm{H}_{5} \mathrm{OH}$, LPG, and formaldehyde is still relatively high. More efforts are needed on studying the long-term stability and reliability of the CNTs-based sensors, which has been less studied. Nevertheless, the discovery of carbon nanotubes, a group of outstanding nanomaterials, provides excellent candidates for gas sensors, especially for nanosensors which could be vital to their specific applications such as in space shuttles and satellites. Sensors based on single SWCNT FET, well-aligned CNTs structure for field emission devices, or electrochemical systems are the most promising devices for practical applications.

\section{Acknowledgments}

Financial support of the work by the Research Fund for the Doctoral Program of Higher Education (RFDP) under Grant 20070561008 and the Natural Science Foundation of China under Grant 20773041 is greatly acknowledged.

\section{References}

[1] Y. Saito, G. Dresselhause, and M. S. Dresselhause, Physical Properties of Carbon Nanotubes, Imperial College Press, London, UK, 1998.

[2] H. Dai, "Nanotube growth and characterization," in Carbon Nanotubes, M. S. Dresselhaus, G. Dresselhaus, and P. Avouris, Eds., Springer, Berlin, Germany, 2001.
[3] S. Iijima, "Helical microtubules of graphitic carbon," Nature, vol. 354 , no. 6348 , pp. 56-58, 1991.

[4] S. Iijima and T. Ichihashi, "Single-shell carbon nanotubes of 1nm diameter," Nature, vol. 363, no. 6430, pp. 603-605, 1993.

[5] J. J. Davis, K. S. Coleman, B. R. Azamian, C. B. Bagshaw, and M. L. H. Green, "Chemical and biochemical sensing with modified single walled carbon nanotubes," Chemistry: A European Journal, vol. 9, no. 16, pp. 3732-3739, 2003.

[6] J. Zhao, A. Buldum, J. Han, and J. P. Lu, "Gas molecule adsorption in carbon nanotubes and nanotube bundles," Nanotechnology, vol. 13, no. 2, pp. 195-200, 2002.

[7] J. Kong, N. R. Franklin, C. Zhou, et al., "Nanotube molecular wires as chemical sensors," Science, vol. 287, no. 5453, pp. 622$625,2000$.

[8] J. Zhang, A. Boyd, A. Tselev, M. Paranjape, and P. Barbara, "Mechanism of $\mathrm{NO}_{2}$ detection in carbon nanotube field effect transistor chemical sensors," Applied Physics Letters, vol. 88, no. 12, Article ID 123112, 3 pages, 2006.

[9] T. Helbling, R. Pohle, L. Durrer, et al., "Sensing $\mathrm{NO}_{2}$ with individual suspended single-walled carbon nanotubes," Sensors and Actuators B, vol. 132, no. 2, pp. 491-497, 2008.

[10] S. Peng, K. Cho, P. Qi, and H. Dai, "Ab initio study of CNT $\mathrm{NO}_{2}$ gas sensor," Chemical Physics Letters, vol. 387, no. 4-6, pp. 271-276, 2004.

[11] J. P. Novak, E. S. Snow, E. J. Houser, D. Park, J. L. Stepnowski, and R. A. McGill, "Nerve agent detection using networks of single-walled carbon nanotubes," Applied Physics Letters, vol. 83, no. 19, pp. 4026-4028, 2003.

[12] N. Peng, Q. Zhang, Y. C. Lee, O. K. Tan, and N. Marzari, "Gate modulation in carbon nanotube field effect transistors-based $\mathrm{NH}_{3}$ gas sensors," Sensors and Actuators B, vol. 132, no. 1, pp. 191-195, 2008.

[13] M. Lucci, A. Reale, A. Di Carlo, et al., "Optimization of a $\mathrm{NO}_{x}$ gas sensor based on single walled carbon nanotubes," Sensors and Actuators B, vol. 118, no. 1-2, pp. 226-231, 2006.

[14] J. Li, Y. Lu, Q. Ye, M. Cinke, J. Han, and M. Meyyappan, "Carbon nanotube sensors for gas and organic vapor detection," Nano Letters, vol. 3, no. 7, pp. 929-933, 2003.

[15] R. J. Chen, N. R. Franklin, J. Kong, et al., "Molecular photodesorption from single-walled carbon nanotubes," Applied Physics Letters, vol. 79, no. 14, pp. 2258-2260, 2001.

[16] N. H. Quang, M. Van Trinh, B.-H. Lee, and J.-S. Huh, "Effect of $\mathrm{NH}_{3}$ gas on the electrical properties of single-walled carbon nanotube bundles," Sensors and Actuators B, vol. 113, no. 1, pp. 341-346, 2006.

[17] H.-Q. Nguyen and J.-S. Huh, "Behavior of single-walled carbon nanotube-based gas sensors at various temperatures of treatment and operation," Sensors and Actuators B, vol. 117, no. 2, pp. 426-430, 2006.

[18] O. K. Varghese, P. D. Kichambre, D. Gong, K. G. Ong, E. C. Dickey, and C. A. Grimes, "Gas sensing characteristics of multi-wall carbon nanotubes," Sensors and Actuators B, vol. 81, no. 1, pp. 32-41, 2001.

[19] L. H. Nguyen, T. V. Phi, P. Q. Phan, H. N. Vu, C. Nguyen-Duc, and F. Fossard, "Synthesis of multi-walled carbon nanotubes for $\mathrm{NH}_{3}$ gas detection," Physica E, vol. 37, no. 1-2, pp. 54-57, 2007.

[20] S.-I. Moon, K.-K. Paek, Y.-H. Lee, et al., "Bias-heating recovery of MWCNT gas sensor," Materials Letters, vol. 62, no. 16, pp. 2422-2425, 2008.

[21] J. Suehiro, G. Zhou, and M. Hara, "Detection of partial discharge in $\mathrm{SF}_{6}$ gas using a carbon nanotube-based gas sensor," Sensors and Actuators B, vol. 105, no. 2, pp. 164-169, 2005. 
[22] G. Sun, S. Liu, K. Hua, X. Lv, L. Huang, and Y. Wang, "Electrochemical chlorine sensor with multi-walled carbon nanotubes as electrocatalysts," Electrochemistry Communications, vol. 9, no. 9, pp. 2436-2440, 2007.

[23] J. M. Nugent, K. S. V. Santhanam, A. Rubio, and P. M. Ajayan, "Fast electron transfer kinetics on multiwalled carbon nanotube microbundle electrodes," Nano Letters, vol. 1, no. 2, pp. 87-91, 2001.

[24] R. Ionescu, E. H. Espinosa, E. Sotter, et al., "Oxygen functionalisation of MWNT and their use as gas sensitive thick-film layers," Sensors and Actuators B, vol. 113, no. 1, pp. 36-46, 2006.

[25] J. Suehiro, G. Zhou, H. Imakiire, W. Ding, and M. Hara, "Controlled fabrication of carbon nanotube $\mathrm{NO}_{2}$ gas sensor using dielectrophoretic impedance measurement," Sensors and Actuators B, vol. 108, no. 1-2, pp. 398-403, 2005.

[26] L. Valentini, C. Cantalini, I. Armentano, J. M. Kenny, L. Lozzi, and S. Santucci, "Highly sensitive and selective sensors based on carbon nanotubes thin films for molecular detection," Diamond and Related Materials, vol. 13, no. 4-8, pp. 13011305, 2004.

[27] W.-S. Cho, S.-I. Moon, K.-K. Paek, Y.-H. Lee, J.-H. Park, and B.-K. Ju, "Patterned multiwall carbon nanotube films as materials of $\mathrm{NO}_{2}$ gas sensors," Sensors and Actuators B, vol. 119, no. 1, pp. 180-185, 2006.

[28] T. Ueda, M. M. H. Bhuiyan, H. Norimatsu, S. Katsuki, T. Ikegami, and F. Mitsugi, "Development of carbon nanotubebased gas sensors for $\mathrm{NO}_{x}$ gas detection working at low temperature," Physica E, vol. 40, no. 7, pp. 2272-2277, 2008.

[29] N. D. Hoa, N. Van Quy, Y. Cho, and D. Kim, "An ammonia gas sensor based on non-catalytically synthesized carbon nanotubes on an anodic aluminum oxide template," Sensors and Actuators B, vol. 127, no. 2, pp. 447-454, 2007.

[30] C. S. Huang, B. R. Huang, Y. H. Jang, M. S. Tsai, and C. Y. Yeh, “Three-terminal CNTs gas sensor for $\mathrm{N}_{2}$ detection," Diamond and Related Materials, vol. 14, no. 11-12, pp. 1872-1875, 2005.

[31] M. Lucci, P. Regoliosi, A. Reale, et al., "Gas sensing using single wall carbon nanotubes ordered with dielectrophoresis," Sensors and Actuators B, vol. 111-112, pp. 181-186, 2005.

[32] H.-L. Hsu, J.-M. Jehng, Y. Sung, L.-C. Wang, and S.-R. Yang, "The synthesis, characterization of oxidized multi-walled carbon nanotubes, and application to surface acoustic wave quartz crystal gas sensor," Materials Chemistry and Physics, vol. 109, no. 1, pp. 148-155, 2008.

[33] J. Mäklin, T. Mustonen, K. Kordás, S. Saukko, G. Tóth, and J. Vähäkangas, "Nitric oxide gas sensors with functionalized carbon nanotubes," Physica Status Solidi B, vol. 244, no. 11, pp. 4298-4302, 2007.

[34] D. Fu, H. Lim, Y. Shi, et al., "Differentiation of gas molecules using flexible and all-carbon nanotube devices," Journal of Physical Chemistry C, vol. 112, no. 3, pp. 650-653, 2008.

[35] T. H. Tran, J.-W. Lee, K. Lee, Y. D. Lee, and B.-K. Ju, "The gas sensing properties of single-walled carbon nanotubes deposited on an aminosilane monolayer," Sensors and Actuators B, vol. 129, no. 1, pp. 67-71, 2008.

[36] P. Qi, O. Vermesh, M. Grecu, et al., "Toward large arrays of multiplex functionalized carbon nanotube sensors for highly sensitive and selective molecular detection," Nano Letters, vol. 3, no. 3, pp. 347-351, 2003.

[37] E. Bekyarova, M. Davis, T. Burch, et al., "Chemically functionalized single-walled carbon nanotubes as ammonia sensors," Journal of Physical Chemistry B, vol. 108, no. 51, pp. 1971719720, 2004.
[38] T. Zhang, S. Mubeen, E. Bekyarova, et al., "Poly(maminobenzene sulfonic acid) functionalized single-walled carbon nanotubes based gas sensor," Nanotechnology, vol. 18, no. 16, Article ID 165504, 6 pages, 2007.

[39] K. H. An, S. Y. Jeong, H. R. Hwang, and Y. H. Lee, "Enhanced sensitivity of a gas sensor incorporating single-walled carbon nanotube-polypyrrole nanocomposites," Advanced Materials, vol. 16, no. 12, pp. 1005-1009, 2004.

[40] X. Liu, J. Ly, S. Han, et al., "Synthesis and electronic properties of individual single-walled carbon nanotube/polypyrrole composite nanocables," Advanced Materials, vol. 17, no. 22, pp. 2727-2732, 2005.

[41] P. Santhosh, K. M. Manesh, A. Gopalan, and K.-P. Lee, "Novel amperometric carbon monoxide sensor based on multiwall carbon nanotubes grafted with polydiphenylamineFabrication and performance," Sensors and Actuators B, vol. 125, no. 1, pp. 92-99, 2007.

[42] J. K. Abraham, B. Philip, A. Witchurch, V. K. Varadan, and C. C. Reddy, "A compact wireless gas sensor using a carbon nanotube/PMMA thin film chemiresistor," Smart Materials and Structures, vol. 13, no. 5, pp. 1045-1049, 2004.

[43] K. S. V. Santhanam, R. Sangoi, and L. Fuller, "A chemical sensor for chloromethanes using a nanocomposite of multiwalled carbon nanotubes with poly(3-methylthiophene)," Sensors and Actuators B, vol. 106, no. 2, pp. 766-771, 2005.

[44] B. Zhang, R. W. Fu, M. Q. Zhang, X. M. Dong, P. L. Lan, and J. S. Qiu, "Preparation and characterization of gas-sensitive composites from multi-walled carbon nanotubes/polystyrene," Sensors and Actuators B, vol. 109, no. 2, pp. 323-328, 2005.

[45] L. Niu, Y. Luo, and Z. Li, "A highly selective chemical gas sensor based on functionalization of multi-walled carbon nanotubes with poly(ethylene glycol)," Sensors and Actuators $B$, vol. 126, no. 2, pp. 361-367, 2007.

[46] L. Valentini, V. Bavastrello, E. Stura, I. Armentano, C. Nicolini, and J. M. Kenny, "Sensors for inorganic vapor detection based on carbon nanotubes and poly(o-anisidine) nanocomposite material," Chemical Physics Letters, vol. 383, no. 5-6, pp. 617622, 2004.

[47] C. Wei, L. Dai, A. Roy, and T. B. Tolle, "Multifunctional chemical vapor sensors of aligned carbon nanotube and polymer composites," Journal of the American Chemical Society, vol. 128, no. 5, pp. 1412-1413, 2006.

[48] A. Ruiz, J. Arbiol, A. Cirera, A. Cornet, and J. R. Morante, "Surface activation by Pt-nanoclusters on titania for gas sensing applications," Materials Science and Engineering C, vol. 19, no. 1-2, pp. 105-109, 2002.

[49] J. Kong, M. G. Chapline, and H. J. Dai, "Functionalized carbon nanotubes for molecular hydrogen sensors," Advanced Materials, vol. 13, no. 18, pp. 1384-1386, 2001.

[50] I. Sayago, E. Terrado, M. Aleixandre, et al., "Novel selective sensors based on carbon nanotube films for hydrogen detection," Sensors and Actuators B, vol. 122, no. 1, pp. 75-80, 2007.

[51] S. Mubeen, T. Zhang, B. Yoo, M. A. Deshusses, and N. V. Myung, "Palladium nanoparticles decorated single-walled carbon nanotube hydrogen sensor," Journal of Physical Chemistry C, vol. 111, no. 17, pp. 6321-6327, 2007.

[52] Y. Sun and H. H. Wang, "Electrodeposition of Pd nanoparticles on single-walled carbon nanotubes for flexible hydrogen sensors," Applied Physics Letters, vol. 90, no. 21, Article ID 213107, pp. 1-3, 2007.

[53] J. Sippel-Oakley, H.-T. Wang, B. S. Kang, et al., "Carbon nanotube films for room temperature hydrogen sensing," Nanotechnology, vol. 16, no. 10, pp. 2218-2221, 2005. 
[54] D. Ding, Z. Chen, S. Rajaputra, and V. Singh, "Hydrogen sensors based on aligned carbon nanotubes in an anodic aluminum oxide template with palladium as a top electrode," Sensors and Actuators B, vol. 124, no. 1, pp. 12-17, 2007.

[55] Y. Lu, J. Li, J. Han, et al., "Room temperature methane detection using palladium loaded single-walled carbon nanotube sensors," Chemical Physics Letters, vol. 391, no. 4-6, pp. 344348, 2004.

[56] Y. Li, H. Wang, Y. Chen, and M. Yang, "A multi-walled carbon nanotube/palladium nanocomposite prepared by a facile method for the detection of methane at room temperature," Sensors and Actuators B, vol. 132, no. 1, pp. 155-158, 2008.

[57] M. K. Kumar and S. Ramaprabhu, "Nanostructured Pt functionlized multiwalled carbon nanotube based hydrogen sensor," Journal of Physical Chemistry B, vol. 110, no. 23, pp. 11291-11298, 2006.

[58] M. K. Kumar and S. Ramaprabhu, "Palladium dispersed multiwalled carbon nanotube based hydrogen sensor for fuel cell applications," International Journal of Hydrogen Energy, vol. 32, no. 13, pp. 2518-2526, 2007.

[59] M. K. Kumar, A. L. M. Reddy, and S. Ramaprabhu, "Exfoliated single-walled carbon nanotube-based hydrogen sensor," Sensors and Actuators B, vol. 130, no. 2, pp. 653-660, 2008.

[60] G. V. Kamarchuk, I. G. Kolobov, A. V. Khotkevich, et al., "New chemical sensors based on point heterocontact between single wall carbon nanotubes and gold wires," Sensors and Actuators B, vol. 134, no. 2, pp. 1022-1026, 2008.

[61] M. Penza, G. Cassano, R. Rossi, et al., "Enhancement of sensitivity in gas chemiresistors based on carbon nanotube surface functionalized with noble metal $(\mathrm{Au}, \mathrm{Pt})$ nanoclusters," Applied Physics Letters, vol. 90, no. 17, pp. 171231171233, 2007.

[62] E. H. Espinosa, R. Ionescu, C. Bittencourt, et al., "Metaldecorated multi-wall carbon nanotubes for low temperature gas sensing," Thin Solid Films, vol. 515, no. 23, pp. 8322-8327, 2007.

[63] A. Star, V. Joshi, S. Skarupo, D. Thomas, and J.-C. P. Gabriel, "Gas sensor array based on metal-decorated carbon nanotubes," Journal of Physical Chemistry B, vol. 110, no. 42, pp. 21014-21020, 2006.

[64] Y. Lu, C. Partridge, M. Meyyappan, and J. Li, "A carbon nanotube sensor array for sensitive gas discrimination using principal component analysis," Journal of Electroanalytical Chemistry, vol. 593, no. 1-2, pp. 105-110, 2006.

[65] B.-Y. Wei, M.-C. Hsu, P.-G. Su, H.-M. Lin, R.-J. Wu, and H.-J. $\mathrm{Lai}$, "A novel $\mathrm{SnO}_{2}$ gas sensor doped with carbon nanotubes operating at room temperature," Sensors and Actuators B, vol. 101, no. 1-2, pp. 81-89, 2004.

[66] J. Gong, J. Sun, and Q. Chen, "Micromachined sol-gel carbon nanotube $/ \mathrm{SnO}_{2}$ nanocomposite hydrogen sensor," Sensors and Actuators B, vol. 130, no. 2, pp. 829-835, 2008.

[67] N. D. Hoa, N. V. Quy, Y. S. Cho, and D. Kim, "Nanocomposite of SWCNTs and $\mathrm{SnO}_{2}$ fabricated by soldering process for ammonia gas sensor application," Physical Status Solidi A, vol. 204, no. 6, pp. 1820-1824, 2007.

[68] Y.-L. Liu, H.-F. Yang, Y. Yang, Z.-M. Liu, G.-L. Shen, and R.-Q. $\mathrm{Yu}$, "Gas sensing properties of tin dioxide coated onto multiwalled carbon nanotubes," Thin Solid Films, vol. 497, no. 1-2, pp. 355-360, 2006.

[69] Y. Chen, C. Zhu, and T. Wang, "The enhanced ethanol sensing properties of multi-walled carbon nanotubes $/ \mathrm{SnO}_{2}$ core/shell nanostructures," Nanotechnology, vol. 17, no. 12, pp. 30123017, 2006.
[70] E. H. Espinosa, R. Ionescu, B. Chambon, et al., "Hybrid metal oxide and multiwall carbon nanotube films for low temperature gas sensing," Sensors and Actuators B, vol. 127, no. 1, pp. 137-142, 2007.

[71] N. Van Hieu, L.T. B. Thuy, and N. D. Chien, "Highly sensitive thin film $v$ gas sensor operating at room temperature based on $\mathrm{SnO}_{2} / \mathrm{MWCNTs}$ composite," Sensors and Actuators B, vol. 129, no. 2, pp. 888-895, 2008.

[72] J. Wang, L. Liu, S.-Y. Cong, J.-Q. Qi, and B.-K. Xu, "An enrichment method to detect low concentration formaldehyde," Sensors and Actuators B, vol. 134, no. 2, pp. 1010-1015, 2008.

[73] C. Bittencourt, A. Felten, E. H. Espinosa, et al., "WO 3 films modified with functionalised multi-wall carbon nanotubes: morphological, compositional and gas response studies," Sensors and Actuators B, vol. 115, no. 1, pp. 33-41, 2006.

[74] M. Sánchez, R. Guirado, and M. E. Rincón, "Multiwalled carbon nanotubes embedded in sol-gel derived $\mathrm{TiO}_{2}$ matrices and their use as room temperature gas sensors," Journal of Materials Science: Materials in Electronics, vol. 18, no. 11, pp. 1131-1136, 2007.

[75] E. Llobet, E. H. Espinosa, E. Sotter, et al., "Carbon nanotube$\mathrm{TiO}_{2}$ hybrid films for detecting traces of $\mathrm{O}_{2}$," Nanotechnology, vol. 19, no. 37, Article ID 375501, 11 pages, 2008.

[76] N. Van Duy, N. Van Hieu, P. T. Huy, N. D. Chien, M. Thamilselvan, and J. Yi, "Mixed $\mathrm{SnO}_{2} / \mathrm{TiO}_{2}$ included with carbon nanotubes for gas-sensing application," Physica E, vol. 41, no. 2, pp. 258-263, 2008.

[77] S. Peng and K. Cho, "Ab initio study of doped carbon nanotube sensors," Nano Letters, vol. 3, no. 4, pp. 513-517, 2003.

[78] R. Wang, D. Zhang, W. Sun, Z. Han, and C. Liu, "A novel aluminum-doped carbon nanotubes sensor for carbon monoxide," Journal of Molecular Structure, vol. 806, no. 1-3, pp. 93-97, 2007.

[79] R. Wang, D. Zhang, Y. Zhang, and C. Liu, "Boron-doped carbon nanotubes serving as a novel chemical sensor for formaldehyde," Journal of Physical Chemistry B, vol. 110, no. 37, pp. 18267-18271, 2006.

[80] Y. Zhang, D. Zhang, and C. Liu, "Novel chemical sensor for cyanides: boron-doped carbon nanotubes," Journal of Physical Chemistry B, vol. 110, no. 10, pp. 4671-4674, 2006.

[81] L. Bai and Z. Zhou, "Computational study of B- or N-doped single-walled carbon nanotubes as $\mathrm{NH}_{3}$ and $\mathrm{NO}_{2}$ sensors," Carbon, vol. 45, no. 10, pp. 2105-2110, 2007. 

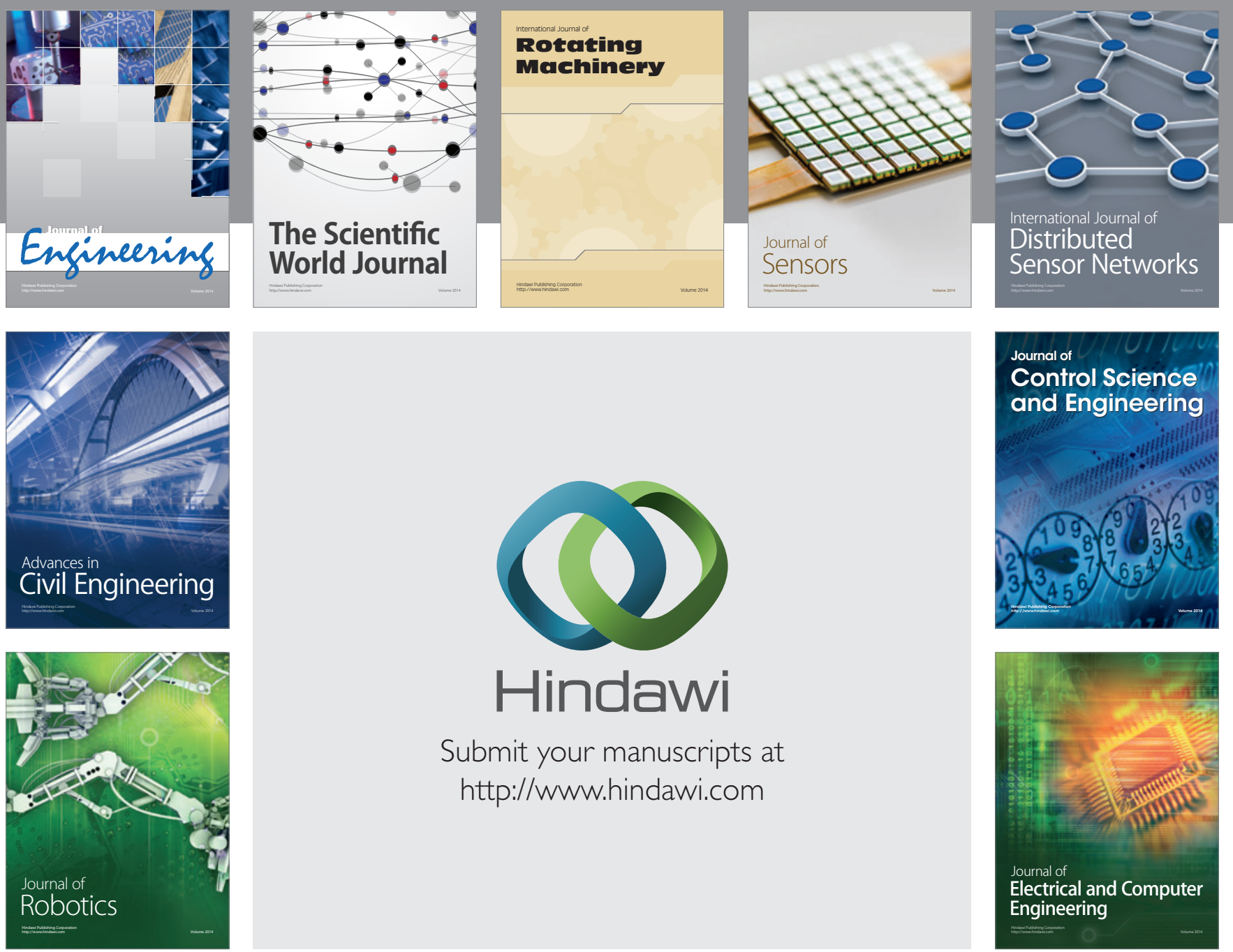

Submit your manuscripts at

http://www.hindawi.com
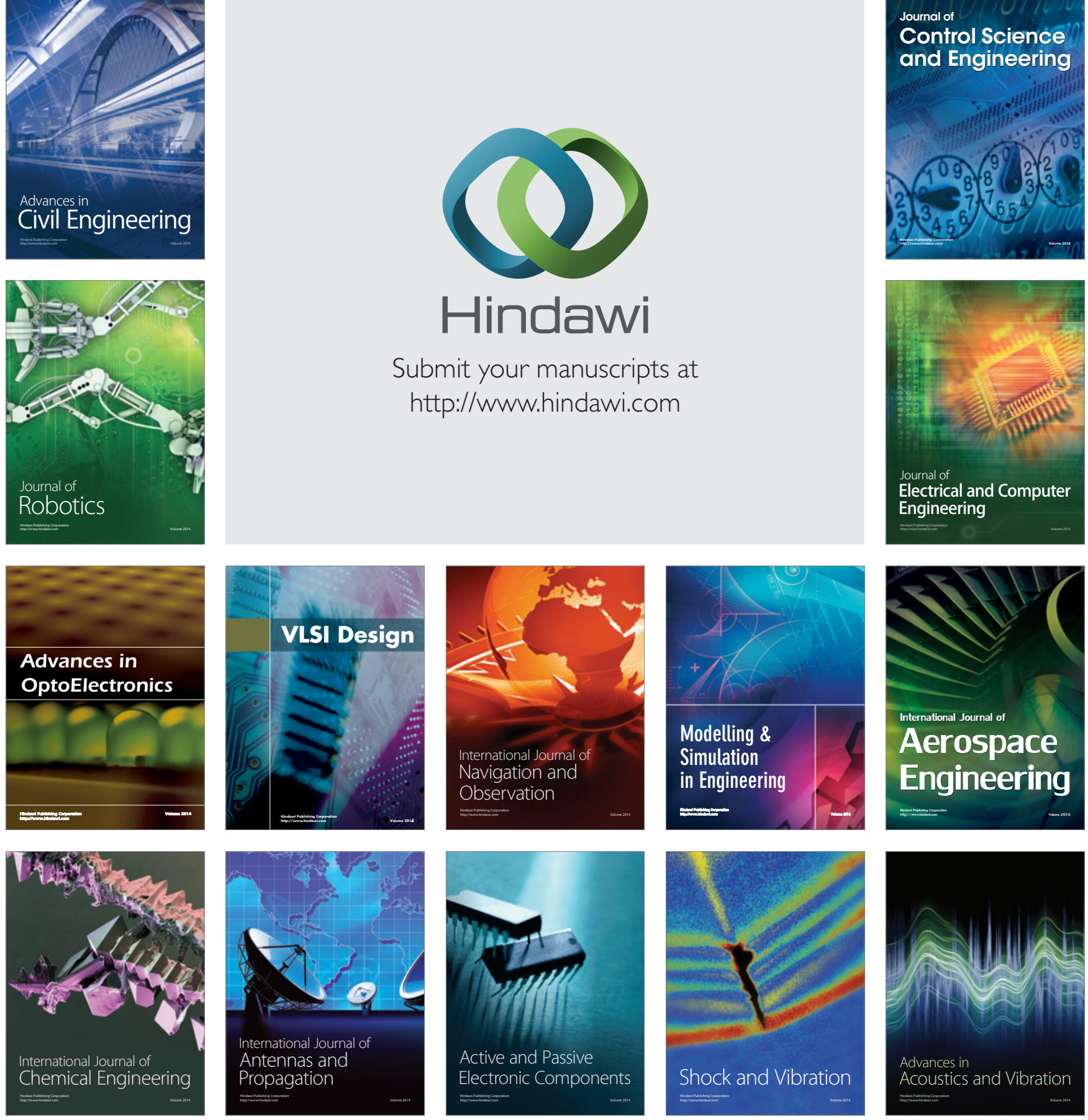